\title{
Photoneutron Logging System for Direct Uranium Ore-Grade Determination
}

\author{
Michael P. Baker
}

Thomas Marks

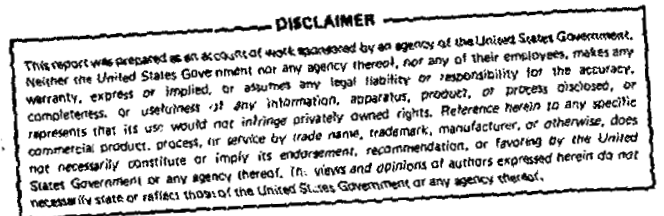




\section{CONTENTS}

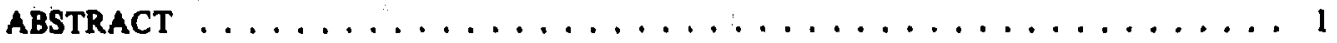

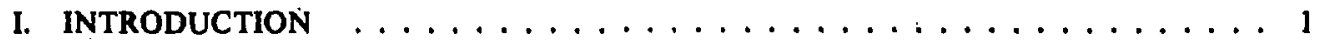

A. Comparison of Uranium Assay Methods $\ldots \ldots \ldots \ldots \ldots \ldots \ldots$

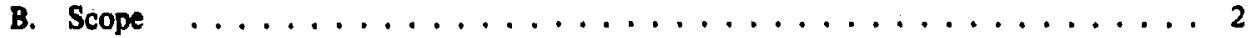

II. PROBE DESCRIPTION $\ldots \ldots \ldots \ldots \ldots \ldots \ldots \ldots \ldots \ldots \ldots$

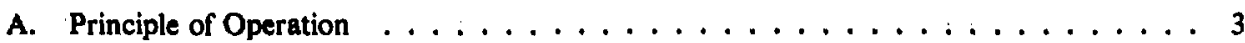

B. Method of Operation $\ldots \ldots \ldots \ldots \ldots \ldots \ldots \ldots$

III. TESTS AT THE GRAND JUNCTION CALIBRATION FACILITY $\ldots \ldots \ldots$

A. Facility Description ....................... 5

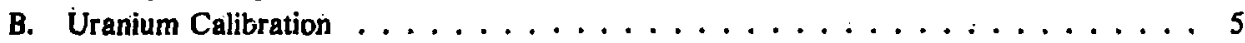

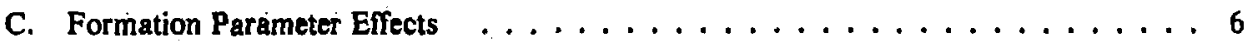

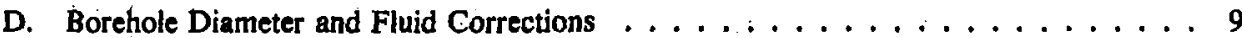

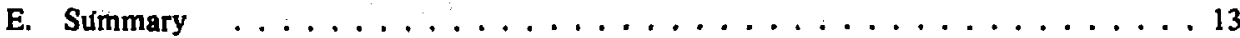

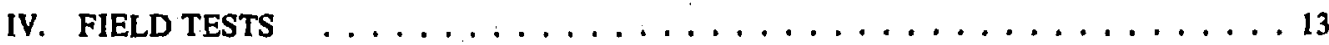

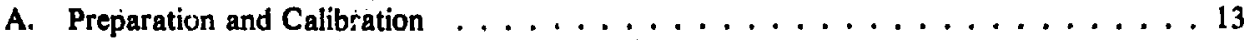

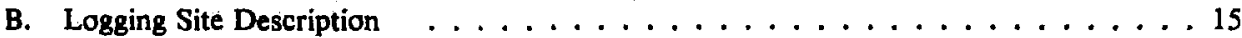

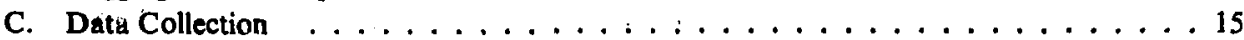

D. Comparison with Other Techniques $\ldots \ldots \ldots \ldots \ldots$

V. CONCLUSIONS AND SUGGESTIONS FOR FURTHER DEVELOPMENT _ . . . . 18

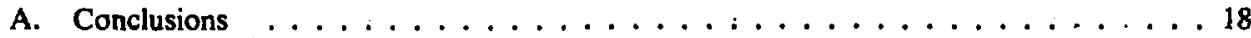

B. Suggestions for Further Development $\ldots \ldots \ldots \ldots \ldots \ldots$

1. Assay Interpretation $\ldots \ldots \ldots \ldots \ldots$

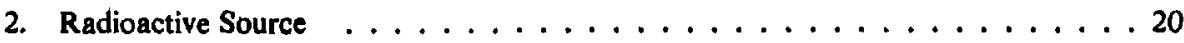

3. Probe and Cask ......................... 20

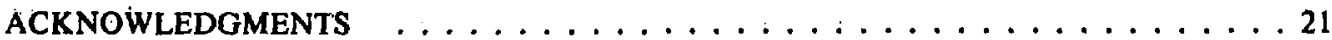

APPENDIX A. DETAILED PROBE DESCRIPTION $\ldots \ldots \ldots \ldots \ldots \ldots$

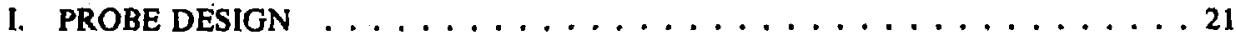

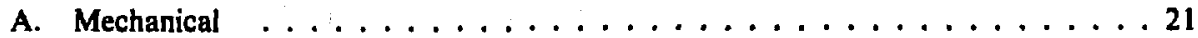

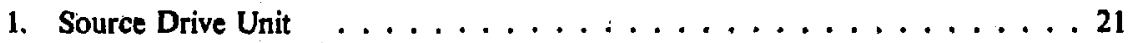

2. Probe Physics and Electrical Section $\ldots \ldots \ldots 22$

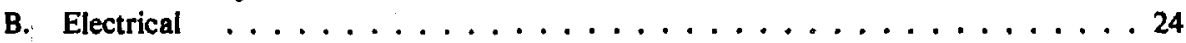

1. General Description ... . . . . . . . . . . . . . . 24

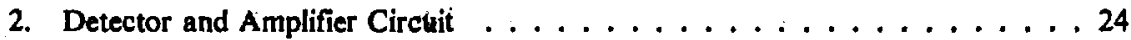

3. Source Position Control and Monitor . . . . . . . . . . . . . . 24

4. Power Supply Circuit . . . . . . . . . . . . . . . . 25

5. Uphole Electronics System .................... 25

II. SOURCE STORAGE CONTAINER $\ldots \ldots \ldots \ldots \ldots$

A. DOT Requirements .................... 26

B. Mechanical Design ..................... 27 
APPENDIX B. ANALYSIS OF GRAND JUNCTION CALIBRATION MODEL SAMPLES . 28 APPENDIX C. LOGGING VEHICLE PREPARATION AND OPERATION $\ldots \ldots \ldots 31$

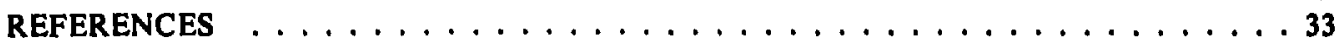




\section{LIST OF TABLES}

I. Formation Parameters for A and D Models at DOE Grand Junction Calibration

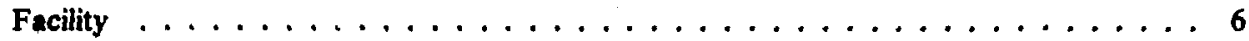

II. Photoneutron-Based Logging Probe Calibration Data . . . . . . . . . . . . 8

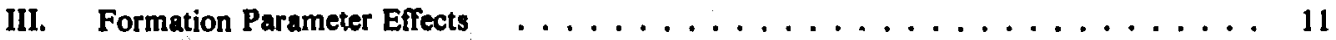

IV. Borehole Diameter and Fluid Calibration (D Model) $\ldots \ldots \ldots \ldots$

V. Comparison of Results of Various Logging Techniques with Core Sample Analysis _ . . 18

VI. Comparison of Results of Various Logging Techniques in a Disequilibrated Zone _ . . . . 19

VII. Summary of Photoneutron Exploration System Features $\ldots \ldots \ldots$

B-1. Crushed Concrete Samples Used in Analytical Chemistry Tests at Los Alamos . . . . . 28

B-II. Elemental Concentration of Crushed Concrete Samples . . . . . . . . . . . . . 29

B-III. Comparison of Assigned Ore Grades and Los Alamos X-Ray Fluorescence

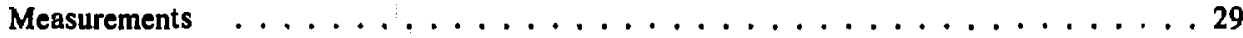

B-IV. Comparison of Assigned Ore Grades and Los Alamos Isotope Dilution Mass Spectrometry Measurements . . . . . . . . . . . . . . . . . . . . . . 2 9

B-V. Atomic Emission Spectroscopy Analysis for Lithium, Boron, Cadmium, Barium,

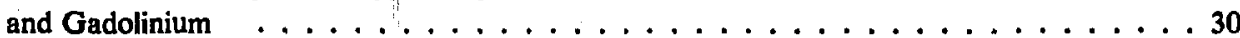




\title{
PHOTONEUTRON LOGGING SYSTEM FOR DIRECT URANIUM ORE-GRADE DETERMINATION
}

by

Michael P. Baker and Thomas Marks

\begin{abstract}
A prototype photoneutron probe for direct uranium assay in exploratory boreholes has been built and field tested by the Los Alamos National Laboratory. An $\sim 10-\mathrm{Ci}$ ${ }^{124} \mathrm{Sb}$ gamma-ray source together with a beryllium converter is used to produce neutrons that diffuse into the surrounding formation and cause fissions in any ${ }^{235} U$ present. The fission neutrons that return to the probe are energy analyzed and counted by a high-pressure helium detector, thus indicating the concentration of uranium. The response of the probe was measured in concrete models at the US Department of Energy (Grand Junction, Colorado) calibration facility and found to be $\sim 35$ counts/s for a $1 \% \mathrm{U}_{3} \mathrm{O}_{2}$ concentration in an $11.4-\mathrm{cm}$-diam water-filled borehole ( $4.5 \mathrm{in}$.). The response is linear up to a concentration of at least $0.25 \%$ by weight $\mathrm{U}_{3} \mathrm{O}_{2}$. Effects resulting from changes in formation density, porosity, and neutron absorber content were also quantified, as well as the tool response as a function of borehole diameter and fluid.

A logging vehicle was outfitted, and the photoneutron-based logging system was fielu tested at an exploration site near Cañon City, Colorado. Logging data obtained in several open holes at this site are presented and compared to core chemical analyses and results obtained in the same holes using other logging methods. In about 1 month of field testing, the photoneutron-based uranium exploration system has proved to be simple to use and very reliable.
\end{abstract}

\section{INTRODUCTION}

\section{A. Comparison of Uranium Assay Methods}

Probabiy the simplest method for measuring uranium in boreholes is the counting of gamma. rays resulting ultimately from the presence of uranium. A probe containing a sodium iodide ( $\mathrm{NaI}$ ) detector is a simple, economic, and rugged device for rapidly counting the abundant passive gamma rays, allowing fast and, therefore, inexpensive logging of boreholes. However, the gamma rays that are used (because of their abundance, range, and minimal interference from other sources) are not due directly to the decay of uranium. Instead, they arise from the decay of the uranium daughter products, principally ${ }^{214} \mathrm{Bi}$. There may be varying degrese of disequilibrium between the uranium and the daughter products over geologically significant times as a result of their differing mobilities. When disequilibrium exiets, an erroneous uranium assay will be inferred from the daughter-product gamma-ray counting rate. Exploration companies combat this difficulty by removins core 
amples from a fraction of the boreholes that are drilled (and subsequently logged with NaI probes) and submitting these samples for destructive chemical analysis at a central analytical laboratory. This procedure significantly increases exploration costs but is necessary if uranium ore reserves are to be determined accirately from $\mathrm{NaI}$ logging data.

A more accurate assay of uranium zones using borehole logging probes can be accomplished if one assesses a signal attributable directly to the uranium. As part of the National Uranium Resource Evaluation (NURE) program, the US Department of Energy has provided funding through its prime contractor, Bendix Field Er:jineering Corporation (BFEC), for development of several direct logging methods. These methods offer the opportunity of obtaining in situ ore-grade values without regard to the state of equilibrium of the ore. Thus, fewer core samples would be required and exploration costs could be significantly reduced. Also, the direst nuclear assay methods, when properly calibrated, probably give an improved estimate of the average oregrade near the borehole because their radii of interrogation significantly exceed the radius of borehole core samples.

Three such neutron-based direct logging schemes have been tested in the past few years. In addition, the US Bureau of Mines has recently supported the development, by Princeton Gamma Tech, of a direct uranium assay system, based on a high-resolution intrinsic germanium detector.' This technique assesses the uranium content of an ore-body by counting gamma rays from the decay of ${ }^{234} \mathrm{~Pa}$, a daughter that reaches equilibrium with the parent ${ }^{238} \mathrm{U}$ in approximately 100 days. (These gamma rays are far less abundant than those from ${ }^{214} \mathrm{Bi}$ decay and cannot be resolved with a Nal detector.)

In all the neutron-based methods, a neutron source sends fast neutrons into the surrounding formation. The source neutrons are reduced in energy (moderated) as a result of repeated collisions with nuclei in the formation. After sufficient moderation the source neutrons have a substantial probability for causing any ${ }^{233} U(\sim 0.7 \%$ of total uranium) that may be present to fission. On the average, each fission releases approximately 2 neutrons, each with $\sim 2 \mathrm{MeV}$ of energy. Some of the fission neutrons return to the borehole where they are detected, thereby indicating the presence of uranium. The three methods are distinguished by the neutron-generating source, the fission neutron detector, and the scheme for separating the interrogating neutrons from the resulting fission neutrons.

The method currently under development at Sandia National Laboratories is generally referred to as the prompt-fission-neutron (PFN) technique. ${ }^{2}$ Their probe contains a pulsed neutron generator that produces bursts of $14-\mathrm{MeV}$ neutrons to interrogate the formation. At the probe the returning fission neutrons, which have slowed to the epithermal energy range, are detected by a cadmium-wrapped ${ }^{3} \mathrm{He}$ proportional counter. The neutron detector is gated off during the neutron generator burst so that the source neutrons are not counted.

IRT Corporation has developed a probe based on delayed-neutron activation analysis (DNAA) ${ }^{3}$ that uses spontaneously fissioning ${ }^{232} \mathrm{Cf}$ as a source of interrogating neutrons. The neutron source is mechanically shuttled to a position $\sim 2.4 \mathrm{~m}(8 \mathrm{ft})$ away after an irradiation. After the source is removed from the immediate area, an array of ${ }^{3} \mathrm{He}$ thermal neutron detectors is turned on and counts the delayed neutrons from the uranium fissions.

The technique developed by the Los Alamos National Laboratory, detailed in this report, is generally referred to as the photoneutron method. The interrogating neutrons are produced by the irradiation of beryllium by a high-energy gamma-ray source $\left(\sim 10 \mathrm{Ci}\right.$ of $\left.{ }^{124} \mathrm{Sb}\right)$. The neutrons generated in this manner are lower in energy ( $\sim 24 \mathrm{keV})$ than those used in the two methods mentioned above. Fission neutrons returning from uranium in the surrounding formation are detected by a helium recoil proportional counter. The amplitude of the signal derived from this detector is proportional to the energy of the recoiling helium nuclei following an elastic collision with a neutron. Thus, the recorded pulse height from the detector is related to the energy of the impinging neutron. By counting only neutrons of higher energy than the interrogating neutrons, this system can be operated continuously without shuttling or pulsing the source.

\section{B. Scope}

This report details the work performed by Los Alamos in developing the photoneutron method for uranium assay from a laboratory technique to a reliable, fieldtested exploration system. The laboratory studies performed to demonstrate feasibility and to define the 
appropriate system components are described in an earlier report. The main body of the report here gives a complete description of the method used, the design of the photoneutron probe, and the results of field tests performed at the DOE calibration facilities at Grand Junction, Colorado, and Grants, New Mexico, as well as an exploration site near Cañon City, Colorado. Conclusions and suggestions for further developments are also presented.

Detailed descriptions of the well-logging probe and source transportation cask designs, chemical analyses of samples from the Grand Junction calibration models, and outfitting of the logging vehicle are contained in the appendixes.

\section{PROBE DESCRIPTION}

\section{A. Principle of Operation}

As currently constituted, this photoneutron-based system uses high-energy gamma rays from an $\sim 10-\mathrm{Ci}^{124} \mathrm{Sb}$ source to produce low-energy neutrons through the $(\gamma, n)$ reaction in a beryllium assembly (Fig. 1). Sources are made by reactor irradiation of antimony metal enclosed in a welded stainless steel container (App. A). The lowenergy neutrons generated diffuse into the formation being logged and produce fissions in the uranium present. Only the ${ }^{235} \mathrm{U}$ nuclei $(0.720 \%$ by weight) undergo fission because the interrogating photoneutrons are lower

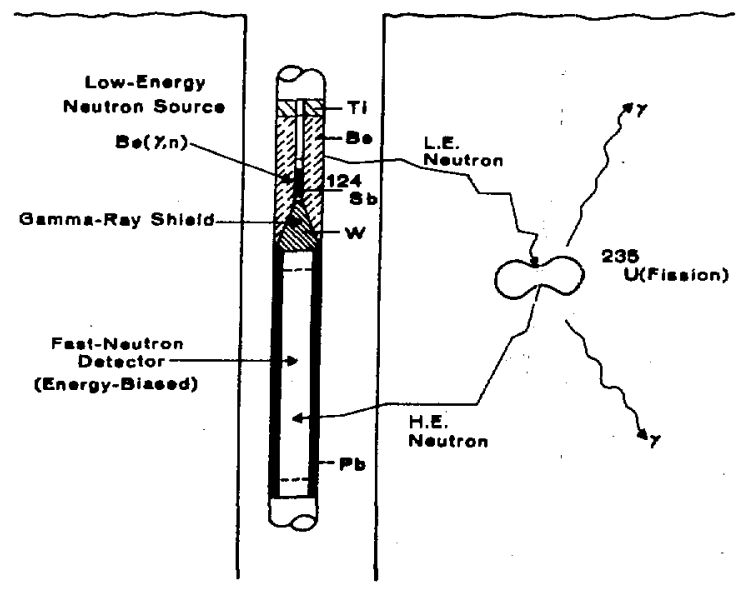

Fig. 1. Photoneutron-based well-logring probe components and the fiesion process in 1 uranium-bearins formation. in energy than the fission threshold of ${ }^{23 \mathrm{~V}} \mathrm{U}$. The fission of a ${ }^{235} \mathrm{U}$ nucleus results, on the average, in the prompt emission of 2 or 3 neutrons with an average energy of $2 \mathrm{MeV}$.

Some of these high-energy fission neutrons that are emitted return to the borehole probe, where they are counted by an 18-atm helium recoil proportional counter biased to prevent the counting of the lower energy source neutrons. Thus, the system is operative $100 \%$ of the time, and no source pulsing or modulation is required. Typical pulse-height spectra are illustrated in Fig. 2, indicating the response of the helium detector in zones with and without uranium. Because it is impractical to store complete pulse-height spectra during a logging operation, typically the spectrum is integrated above a specified threshold and the resulting integral permanently stored. If necessary, the probe can be calibrated at several thresholds and an appropriate threshold value chosen at the logging site.

\section{B. Method of Operation}

The lower section of the probe containing the highenergy gamma-ray source is stored in a depleted uranium cask that serves as a biological shield during transportation to the logging site (Fig. 3). At the site a support plate is placed over the borehole and leveled, and the cask is lowered onto the plate and held securely with guide pins. The upper portion of the probe containing the beryllium converter, the helium detector, and the electronics is stored inside the logging vehicle until the cask has been positioned over the borehole. At this time the logging winch lowers the upper portion of the probe onto the lower portion, enabling the two to be coupled using the threaded collar just above the top of the cask (Fig. 4). A trap door near the bottom of the cask is actuated, allowing the assembled probe containing the gamma-ray source to be lowered into the borehole.

Initially, the gamma-ray source is retained in a cylindrical tungsten shield inside the lower portion of the probe. After the probe is lowered a short distance into the borehole, a remotely controlled motor coupled to a ball lead screw contained in the probe drives the gammaray source up into the beryllium sleeve, and the production of photoneutrons begins. With this method, neutron shielding materials need not be incorporated in the cask because there is negligible neutron production while the 


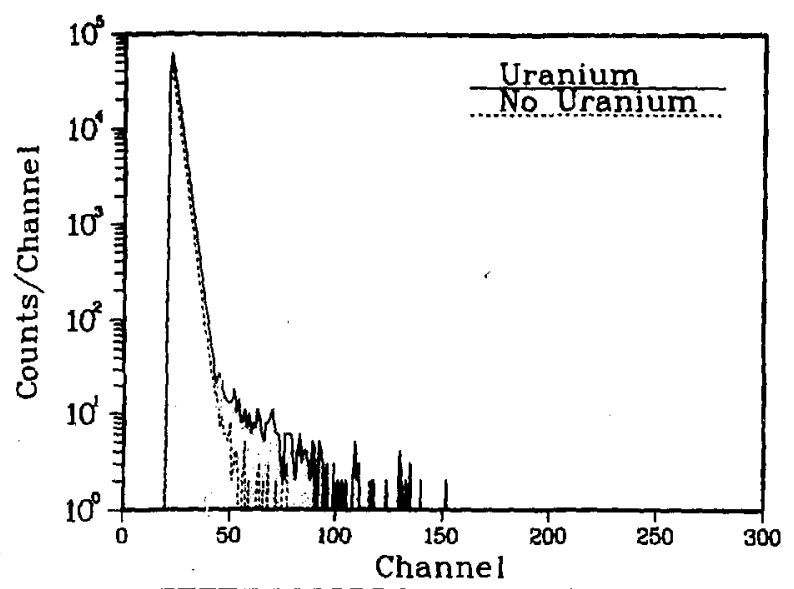

Fig. 2. Helium recoll proportional counter pulse-height spectra obtained in zones with and without uraniurt! present.

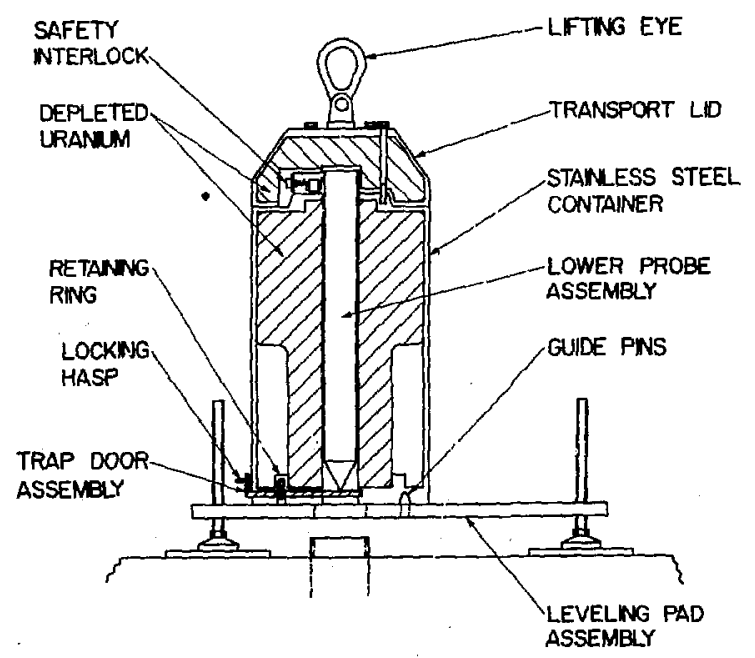

Fig. 3. Source cask and lower section of field prototype photonewtron lowing probe.

probe is above ground. The ground and the borehole fluid shield the operators from neutron and gamma radiation emanating from the probe while the logging operation in the borchole is in progress.

After the logging of the borehole is completed, the gamma-ray source is driven by the motor back into the tungsten cylinder, and the probe is raised back into the cask. (If the operator fails to return the gamma-ray source to its shielded position, an alarm is sounded as the probe enters the cask.) After the probe is returned to the cask, the upper portion of the probe is uncoupled and removed while the lower part remains in the cask. A shielding cap is bolted to the top of the cask during transportation. An integral component of the sap is a tungsten plug that fills the source passageway and prevents radiation streaming. The escape of radiation from the bottom of the cask is limited by the tungsten bull nose at the lower end of the probe.

A radiation-shielding design criterion has been adopted limiting the dose rate to $<10 \mathrm{mR} / \mathrm{h}$ at the surface of the cask. Personnel involved in coupling and decoupling the two parts of the probe experience somewhat higher dose rates to their hands. During one 10-day period of continuous logging exercises, the two persons doing the probe manipulation received an average of $\sim 200 \mathrm{mR}$ to each of their hands. The whole body dose during that period was not significantly above background. The shielding has been reduced in the lower regions of the cask to decrease the weight; however, the gamma-ray source occupies these regions only while it is in transit to and from the borehole. The integrated dose to logging personnel has been small because a majority of the logging operations are performed with personnel at substantial distances from the cask. (An improved design that would reduce the dose received by the operator to still lower levels is discussed in Sec. V.) The cask size 


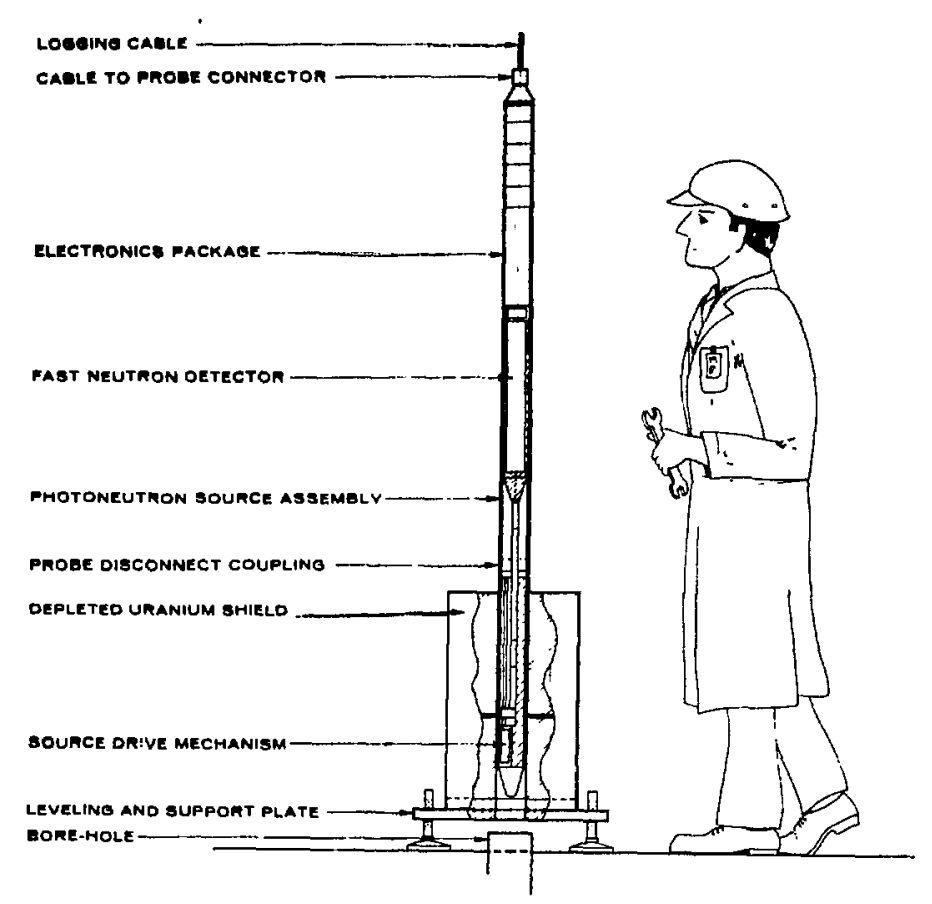

Fiz. 4. Photoneutron-based uranium well-logging probe in use in the field.

required to obtain the design features discussed is $\sim 30 \mathrm{~cm}$ in diameter by $50 \mathrm{~cm}$ high (12 by 20 in.) with a weight of $\sim 750 \mathrm{~kg}(1650 \mathrm{lb})$.

The photoneutron logging probe and cask design are discussed in detail in App. A. Fabrication and assembly details are given in Los Alamos engineering drawing packages Nos. 68Y-155399 (Probe) and 68Y-155400 (Cask). A patent for the photoneutron-based method of uranium exploration has been issued to the DOE.

\section{TESTS AT THE GRAND JUNCTION CALIBRATION FACILITY}

\section{A. Facility Description}

The performance of the probe was initially evaluated at the Grand Junction DOE calibration facility in collaboration with BFEC personnel. Los Alamos provided the photoneutron-based probe, including uphole pulse-processing and control electronics; BFEC supplied a logging vehicle equipped with an ND660 computer-based multichannel analyzer and peripherals.

Static and dynamic data were obtained in the $A$ and $D$ models at the calibration facility. These models were recently constructed specifically for use with boreholelogging probes that feature neutron sources to induce fission in the uranium present.

Measurements conducted in the $\mathbf{A}$ and $\mathbf{D}$ models can be classified in three general categories: (1) calibration-tool response as a function of uranium ore grade with all other parameters fixed; (2) formation parameter effects-tool response as a function of formation density, porosity, and neutron-absorber content changes with ore grade fixed; and (3) borehole diameter calibration-tool response as a function of borehole diameter and fluid with all other parameters fixed.

\section{B. Uranium Calibration}

The calibration of the probe was determined by stutic measurements in models A-1, A-2, and A-3, with both air and water as borehole fluids. Model A-4 was also measured, but the uranium concentration is not uniform with depth and the results were not used in establishine the calibration. Models A-1 through A-4 are each $1.83 \mathrm{~m}$ $(6 \mathrm{ft})$ in diameter and $8.84 \mathrm{~m}(29 \mathrm{ft})$ deep with a vertical, $11.4-\mathrm{cm}$ borehole ( $4.5 \mathrm{in}$.) in the center. There is $\approx 1.52$ m-thick barren zone $(5 \mathrm{ft})$ at the top of each modd, 
followed by a 1,83-m-thick ore zone ( $6 \mathrm{ft}$ ), and finally a 1.22 -m-thick barren zone ( $4 \mathrm{ft}$ ). The remaining $4.27 \mathrm{~m}$ (14 $\mathrm{ft}$ ) at the bottom of the models contain a runout tube. The formation parameters for the ore zones of all models studied are given in Table I. A more complete discussion of the properties of the A models is contained in Ref. 6.

Detailed static scans of models A-3 and A-4, iflustrated in Figs. 5 and 6, respectively, were made with air as the borehole fluid, whereas a more limited number of data points were obtained in the ore zones and barren zones in the other cases. Table II details the calibration results both in terms of response per unit ore grade and response per unit $\mathrm{U}_{3} \mathrm{O}_{2}$ density. The weighted average response per unit $\mathrm{U}_{3} \mathrm{O}_{2}$ density is determined, at least in a relative sense, to better than $\pm 2 \%$ for both water- and air-filled boreholes. These results are shown in the conventional way in Fig. 7. Using the calibration obtained for air-filled boreholes given in Table II, a value of $2279 \pm 4 \mathrm{I} \mathrm{ppm} \mathrm{U}_{3} \mathrm{O}_{2}$ is obtained for the average ore grade in model A-4. This value is surprisingly close to that given in Table $I$ in that the measurement intervals were probably not identical in the two cases.

Including uncertainties for the ore concentrations in the models would yield response uncertainties far greater than the dispersion of the results warrants. The close agreement of the response values in Table II may be fortuitous, but this explanation seems unlikely in the case of four independent observations. Another possible ex- planation is that the estimated uncertainties in the ore grades given in Table $I$ include systematic uncertainties, that is, errors in scale. These, of course, would cancel in the analysis presented in Table II. Finally, it is possible that the stated uncertainties in ore grade for the models are indeed random but were measured over spatial intervals much smaller than the spatial resolution of the present tool. If this were the case, the tool would average over many small measurement intervals with a subsequent reduction in the measurement variations as a function of depth.

A dynamic scan of model $\mathrm{A}-3$ (1550 ppm $\left.\mathrm{U}_{3} \mathrm{O}_{8}\right)$ was also performed. A precision of $\pm 3 \%$ on the ore-gradethickness product was obtained at a logging speed of $0.5 \mathrm{~cm} / \mathrm{s}(1 \mathrm{ft} / \mathrm{min}$ ) with water as the borehole fluid. Data were dumped at 30-s intervals, and a total of $12 \mathrm{~min}$ was required to define both the ore and barren zones. The precision of the ore-grade-thickness product should scale as the square root of the logging speed; that is, a precision of $\pm 9 \%$ would be obtained at a logging speed of $5.1 \mathrm{~cm} / \mathrm{s}(10 \mathrm{ft} / \mathrm{min})$.

\section{Formation Parameter Effects}

Detailed static scans of models A-5 and A-6, shown in Figs. 8 and 9, respectively, were performed to study the effects of variations in formation parameters on the

\begin{tabular}{lcccl}
\hline TABLE I. Formation Parameters for A and D Models at DOE \\
Grand Junction Calibration Facility
\end{tabular}




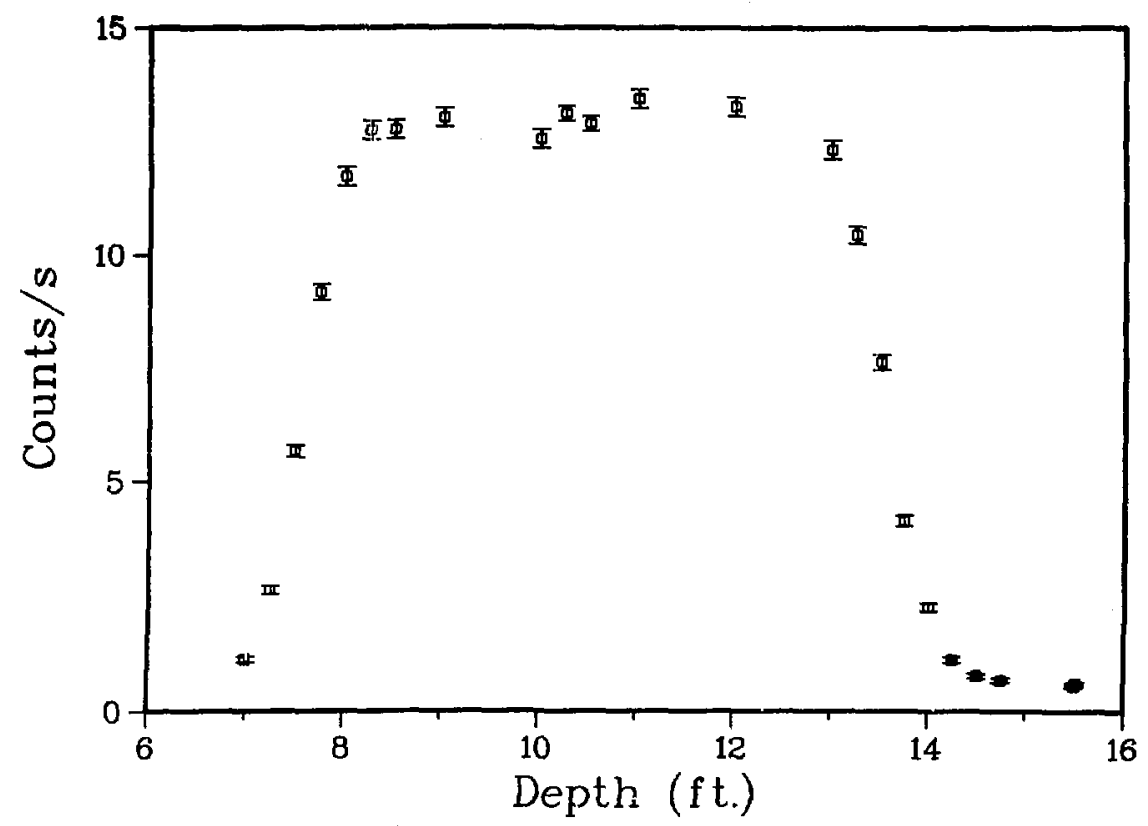

Fig. 5. Response of the photoneutron-based logging probe obtained in a detniled static sum of model A-3.

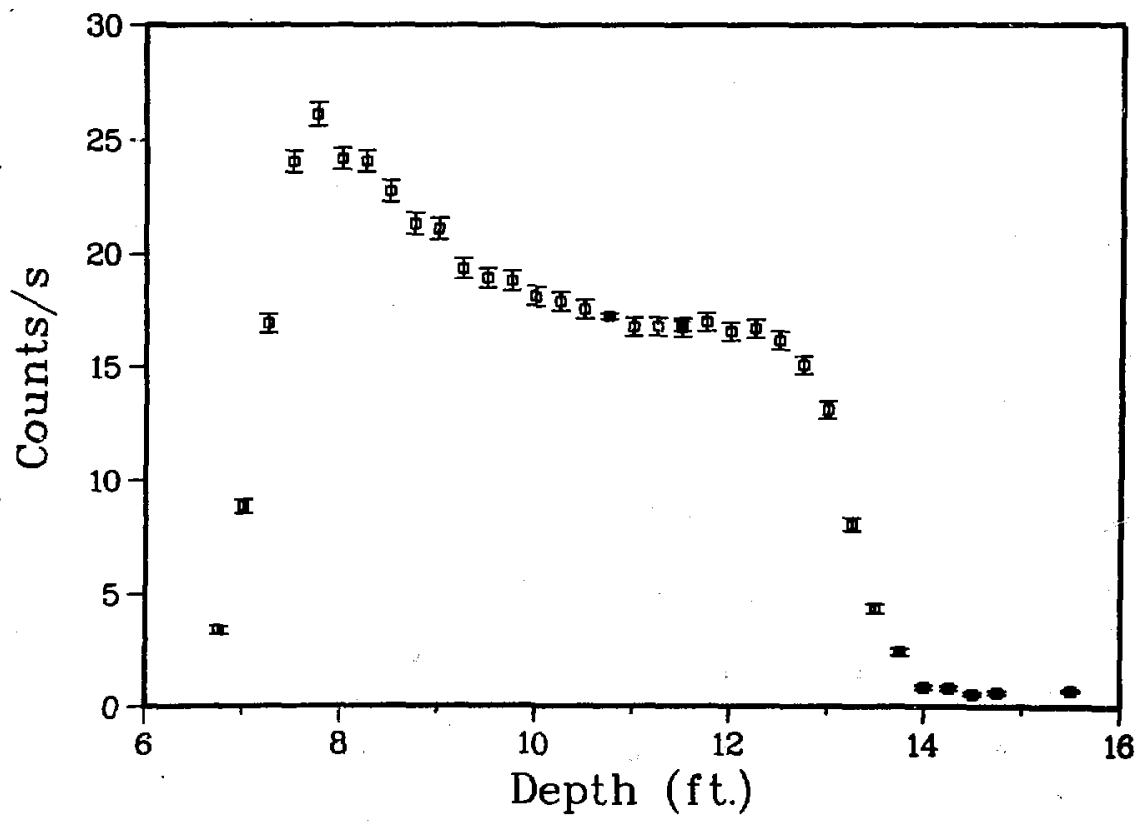

Fis 6. Respone of the photoneutron-baned louging probe obtained in a detailed static mon of model A-4. 


\begin{tabular}{|c|c|c|c|c|}
\hline Model & $\begin{array}{l}\text { Ore Grade } \\
\text { (ppm } \mathrm{U}_{3} \mathrm{O}_{2} \text { ) }\end{array}$ & $\begin{array}{l}\text { Response" } \\
\text { (counts/s) }\end{array}$ & $\begin{array}{c}\text { Response/Ore Grade } \\
\text { (counts/s-ppm } \mathrm{U}_{3} \mathrm{O}_{2} \times 10^{3} \text { ) }\end{array}$ & $\begin{array}{c}\text { Response }^{b} / \mathrm{U}_{3} \mathrm{O}_{3} \text { Density } \\
\text { (counts } / \mathrm{s}-1 \mathrm{~b} / \mathrm{f}^{3} \quad \mathrm{U}_{3} \mathrm{O}_{8} \text { ) } \\
\end{array}$ \\
\hline \multicolumn{5}{|c|}{ (A) Air-Filled } \\
\hline A-1 & 278 & $2.369 \pm 0.047$ & $8.52 \pm 0.17^{c}$ & $61.5 \pm 1.2^{\mathrm{c}}$ \\
\hline A-2 & 757 & $6.048 \pm 0.227$ & $7.99 \pm 0.30$ & $59.0 \pm 2.2$ \\
\hline \multirow[t]{3}{*}{ A-3 } & 1550 & $12.38 \pm 0.31$ & $7.99 \pm 0.20$ & $58.7 \pm 1.5$ \\
\hline & & ighted average: & $8.25 \pm 0.12$ & $60.2 \pm 0.9$ \\
\hline & & $X^{2} / v:^{d}$ & 2.48 & 1.22 \\
\hline \multicolumn{5}{|c|}{ (B) Water-Filled } \\
\hline A-1 & 278 & $1.028 \pm 0.039$ & $3.70 \pm 0.14$ & $26.7 \pm 1.0$ \\
\hline$A-2$ & 757 & $2.599 \pm 0.040$ & $3.38 \pm 0.05$ & $25.0 \pm 0.4$ \\
\hline \multirow[t]{3}{*}{ A-3 } & 1550 & $5.319 \pm 0.153$ & $3.43 \pm 0.10$ & $25.2 \pm 0.7$ \\
\hline & & ghted Average: & $3.42 \pm 0.04$ & $25.2 \pm 0.3$ \\
\hline & . & $\mathrm{X}^{2} / v:^{\mathrm{d}}$ & 2.26 & 1.28 \\
\hline \multicolumn{5}{|c|}{$\begin{array}{l}\text { "All data reported were obtained in the sidewalled configuration. } \\
\text { "Calculated from the ore grade by using the dry bulk density given in Table } \mathrm{I} \text {. } \\
\text { 'The uncertainties in the response per unit ore grade and the response per unit } \mathrm{U}_{3} \mathrm{O}_{8} \text { density have been calculated, } \\
\text { assuming no uncertainties in the ore grades and the dry bulk densities. } \\
\text { dThe } \mathrm{X}^{2} / \nu \text { values have been computed by assuming that the weighted average is the "best fit" value and has no } \\
\text { uncertainty. }\end{array}$} \\
\hline
\end{tabular}

performance of the probe. These models are similar to A-1 through A-4 except that they are constructed with

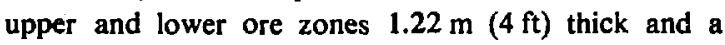
middle barren zone $2.13 \mathrm{~m}(7 \mathrm{ft})$ thick. The parameters of interest are listed in Table $\mathrm{I}$, and the data obtained are summarized in Table III. No data were obtained at

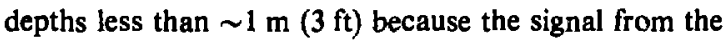
ore was obscured by background fission events induced in the depleted uranium shielding cask as the probe approached the air-ore interface at the top of the models.

Model A-5-T(op) was designed to determine the effects on uranium ore-grade determination caused by variations in the thermal neutron absorption cross section in the formation. This model is similar to A-2 in all respects except for the thermal neutron absorption cross section, which has been increased by a factor of $\sim 4$ through the addition of $\mathrm{B}_{\mathbf{4}} \mathrm{C}$. Referring to the last column of Table III, the effect of the aciditional thermal neutron absorption is to reduce the response of the probe to $\sim 40-45 \%$ of its calibrated response. This result is independent of borehole fluid. Because the low-energy portion of the ${ }^{235} U$ fission cross section accounts for an important fraction of the number of fissions produced in the ore zone, a reduction in response of this order does not seem unreasonable considering the high thermal neutron absorption cross section of boron,

To assess the effects of increased bulk density on fission neutron tool response model $\mathrm{A}-5-\mathrm{B}$ (ottom) was constructed using corundum $\left(\mathrm{Al}_{2} \mathrm{O}_{3}\right)$ rather than sand as the matrix material. For fixed ore grade, one expects the response of the tool to scale directly with density, if all other formation parameters remain fixed. (The improvement in $\mathrm{X}^{2} / \mathrm{v}$ in Table II for response/ $\mathrm{U}_{3} \mathrm{O}_{8}$ density compared to response/ppm $\mathrm{U}_{3} \mathrm{O}_{3}$ confirms this expectation.) Instead, a reduction in response to $\sim 30-35 \%$ of the calibrated response is observed. To investigate this discrepancy a series of crushed concrete samples obtained at the time the models were poured was sent to Los Alamos by BFEC. Analytical chemistry measurements were performed by the Los Alamos Analytical and Instrumental Chemistry Group. Uranium concentration measurements using $\mathrm{x}$-ray fluorescence and isotopedilution mass spectrometry methods indicate that the major discrepancy with model A-5-B is not due to an erroneous assigned uranium concentration. However, atomic emission spectroscopy measurements revealed a much larger than expected concentration of boron in the A-5-B samples. Indeed, it is somewhat higher than that 


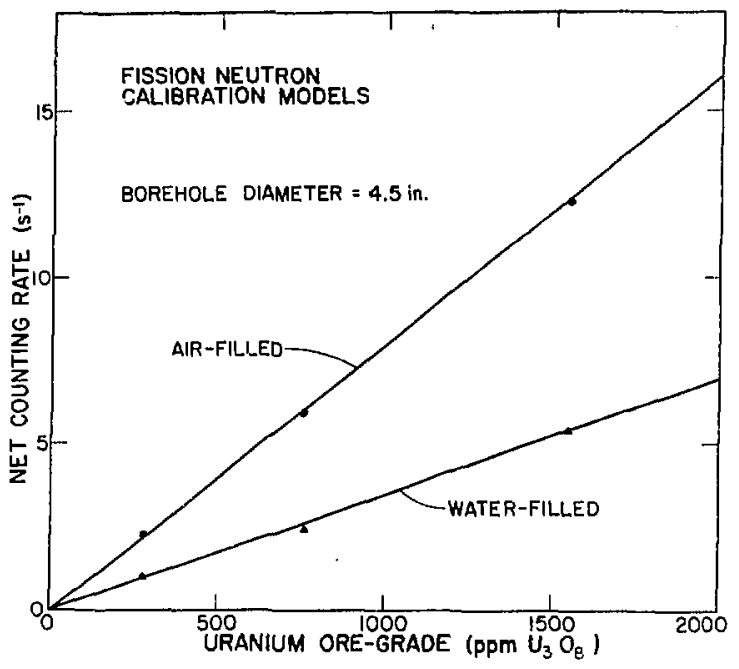

Fig. 7. Calibration data for the photoneutron-based uranium welllogging probe in Grand Junetion models A-1, A-2, and A-3.

found in model A-5-T, which had been deliberately loaded with boron. It was ultimately discovered that the additional boron was a constituent of the corundum used as raw material in the construction of model A-5-B. Detailed results of the sample analyses discussed above are contained in App. B.

Mode? A-6 was designed to determine the influence of changes in formation porosity on the response of fission neutron tools. As indicated in Table I, models A-6-T and A-6-B have markedly different porosities and densities. Assuming that the effect on the response caused by the density difference can be properly corrected, a comparison of models A-6-T and A-6-B will demonstrate the effects caused by porosity alone. This comparison was difficult because the scan of model A-6-B did not indicate a uniform uranium loading as a function of depth (Fig. 9). This nonuniformity has been confirmed by analysis of concrete cores removed when the borehole in model A-6 was drilled.* The three highest measured counting rates in model A-6-B were averaged to obtain the results given in Table III.

*This information supplied by Carl J. Koizumi, Bendix Field Engineering Corporation, Grand Junction, $\mathrm{CO} 81501$.
If this procedure is correct, the model A-6 measurements indicate a small increase in corrected tool response with increasing porosity for both the air- and water-filled cases. Roughly, for every $1 \%$ increase (absolute) in the value of porosity, the response of the tool increases by $1 \%$ (fractional) over this limited range of porosity values (16-29\%). If this range is representative of "real" borehole conditions, porosity variations should not pose a significant problem for the photoneutron-based logging tool.

\section{Borehole Niameter and Fluid Corrections}

Corrections to tool response caused by variations in borehole diameter and fluid were determined in the $\mathbf{D}$ model, which is $4.88 \mathrm{~m}(16 \mathrm{ft})$ in diameter by $8.84 \mathrm{~m}$ (29 ft) deep and contains seven boreholes ranging in diameter from $7.6 \mathrm{~cm}(3 \mathrm{in}$.) to $33 \mathrm{~cm}(13 \mathrm{in}$.). The boreholes were drilled in the pad at $2^{\circ}$ with respect to vertical, ensuring that all measurements are in the sidewalled configuration. There is a $1.52-\mathrm{m}$-thick barren zone $(5 \mathrm{ft}$ ) at the top of the model, followed by a $1.83-\mathrm{m}$ thick ore zone ( $6 \mathrm{ft}$ ), and finally a 1.22-m-thick barren zone ( $4 \mathrm{ft})$. The remaining $4.27 \mathrm{~m}(14 \mathrm{ft}$ ) at the bottom of the model accommodates run-out tubes at the bottom of each borehole. The formation parameters for the ore zone are given in Table I.

Detailed static scans were obtained in the 11.4- and 33.0-cm-diam boreholes ( 4.5 and $13 \mathrm{in}$.) to determine the optimum depth for the borehole diameter and fluid studies. The data, illustrated in Fig. 10, indicate that the uranium is distributed reasonably uniformly throughout the model. The response of the photoneutron-based probe to variations in borehole diameter and fluid at a depth of $2.90 \mathrm{~m}(9.50 \mathrm{ft})$ in the $\mathrm{D}$ model is presented in Table IV and Fig. 11. For the air-filled case, the response is flat for diameters up to $22.9 \mathrm{~cm}$ (9 in.) but declines slowly for larger diameters. The water-filled borehole response is significantly lower than that of the air-filled case, as observed in the A models. The net counting rate falls with borehole diameter, reaching an asymptotic value for diameters of $22.9 \mathrm{~cm}$ ( 9 in.) or more.

As indicated in Table IV, the presence of borehole fluid can readily be determined by observing the background counting rate in the barren formation. In addition, the presence or absence of borehole fluid can be determined by monitoring the tension in the logging cable during a logging operation. However, at this time, method of independently deducing the borehole diameter 


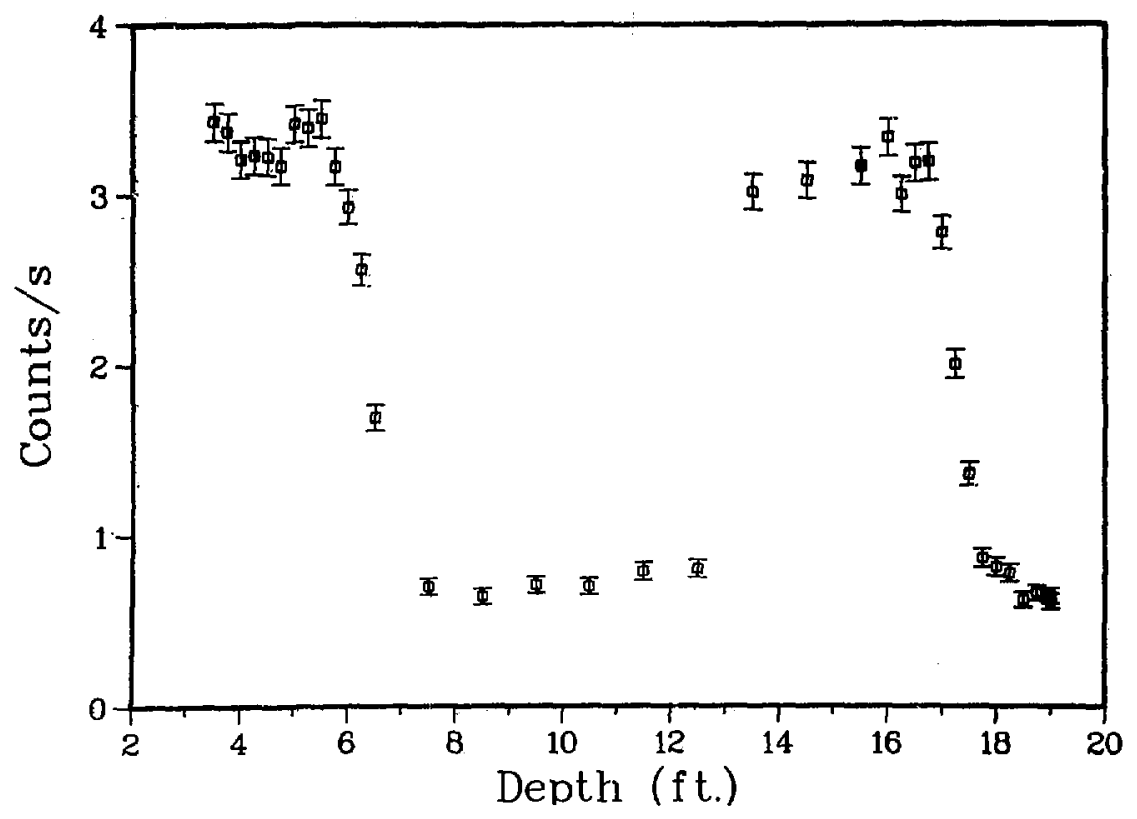

Fig. 8. Response of the photoneutron-based logging probe obtained in a detailed static sum of model A-5.

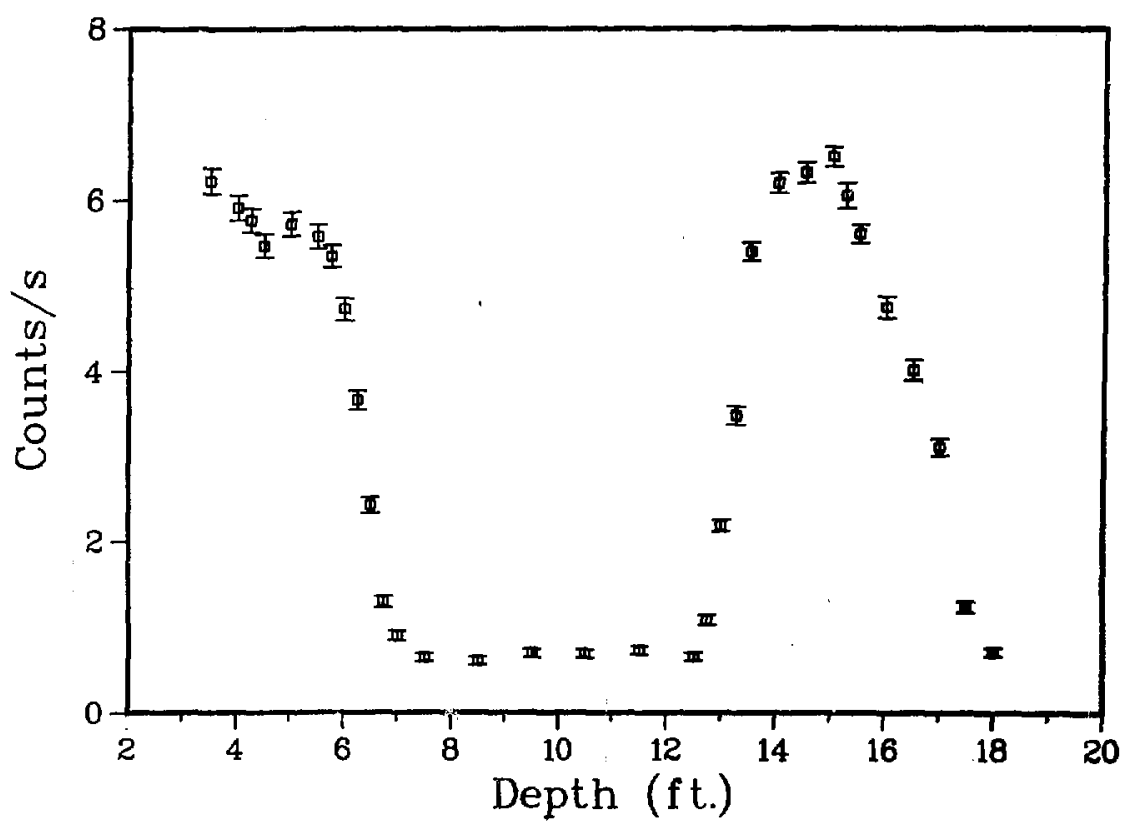

Fig. 9. Response of the photoneutron-based logging probe obtained in a detailed static sum of model A-b. 
TABLE III. Formation Parameter Effects

\begin{tabular}{ccccc}
$\begin{array}{c}\text { Model, } \\
\text { Zone }\end{array}$ & $\begin{array}{c}\text { Ore Grade } \\
\left(\mathrm{ppm} \mathrm{U}_{3} \mathrm{O}_{8}\right)\end{array}$ & $\begin{array}{c}\text { Response } \\
(\text { counts } / \mathrm{s})^{\mathrm{a}}\end{array}$ & $\begin{array}{c}\text { Response } / \mathrm{U}_{3} \mathrm{O}_{8} \text { Density } \\
\left(\text { counts } / \mathrm{s}-1 \mathrm{~b} / \mathrm{ft}^{3} \mathrm{U}_{3} \mathrm{O}_{8}\right)\end{array}$ & $\begin{array}{c}\text { Ratio Relative } \\
\text { to Model } \mathrm{A}-2\end{array}$ \\
\hline
\end{tabular}

(A) Air-Filled

$\begin{array}{lllll}\text { A-5-T } & 780 \pm 32 & 2.686 \pm 0.109 & 25.4 \pm 1.1 & 0.442 \pm 0.019^{b} \\ \text { A-5-B } & 824 \pm 91 & 2.512 \pm 0.148 & 20.4 \pm 1.2 & 0.339 \pm 0.021 \\ \text { A-6-T } & 688 \pm 73 & 5.235 \pm 0.275 & 65.9 \pm 3.5 & 1.09 \pm 0.06 \\ \text { A-6-B } & 700 \pm 149 & 5.701 \pm 0.219 & 59.1 \pm 2.3 & 0.982 \pm 0.041\end{array}$

(B) Water-Filled

$\begin{array}{lllll}\text { A-5-T } & 780 \pm 32 & 1.088 \pm 0.054 & 10.3 \pm 0.5 & 0.409 \pm 0.020 \\ \text { A-5-B } & 824 \pm 91 & 0.922 \pm 0.051 & 7.48 \pm 0.41 & 0.297 \pm 0.017 \\ \text { A-6-T } & 688 \pm 73 & 2.149 \pm 0.071 & 27.1 \pm 0.9 & 1.08 \pm 0.04 \\ \text { A-6-B } & 700 \pm 149 & 2.290 \pm 0.073 & 23.7 \pm 0.8 & 0.940 \pm 0.034\end{array}$

All data reported were obtained in the sidewalled configuration.

buncertainties quoted in this column assume no uncertainty in the $\mathrm{U}_{3} \mathrm{O}_{8}$ concentration.

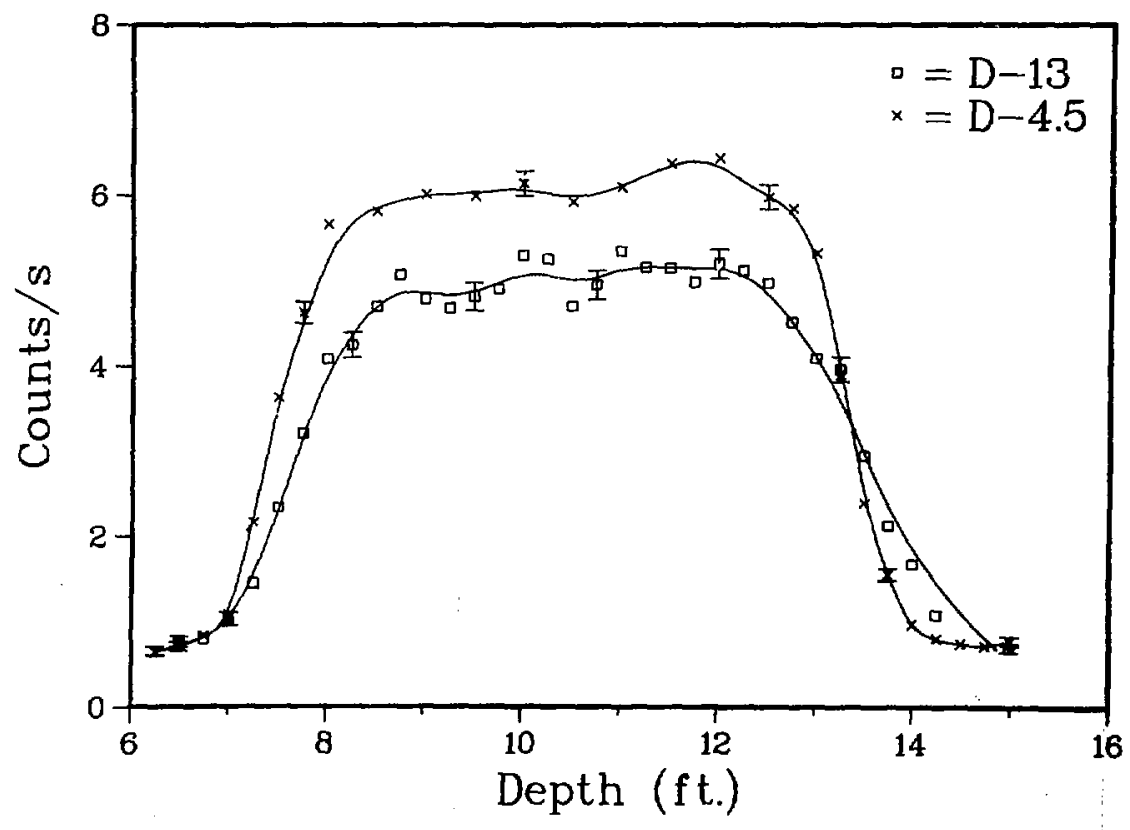

Fig. 10. Response of the photoneutron-based logging probe obtained in detailed static scans of the D-model in the 11.4- and 33.0-cm-diam boreholes (4.5 and $13.0 \mathrm{in}$.). 


\begin{tabular}{|c|c|c|}
\hline $\begin{array}{l}\text { Borehole Diameter } \\
\text { cm (in.) }\end{array}$ & $\begin{array}{c}\text { Air-Filled } \\
\text { Counting Rate }\end{array}$ & $\begin{array}{c}\text { Water-Filled } \\
\text { Counting Rate }\end{array}$ \\
\hline $11.4(4.50)$ & $5.37 \pm 0.22$ & $2.18 \pm 0.10$ \\
\hline $15.2(6.00)$ & $5.54 \pm 0.40$ & $1.71 \pm 0.18$ \\
\hline $19.2(7.56)$ & $5.44 \pm 0.16$ & $1.50 \pm 0.07$ \\
\hline $22.9(9.00)$ & $5.36 \pm 0.16$ & $1.25 \pm 0.06$ \\
\hline $27.9(11.00)$ & $4.71 \pm 0.15$ & $1.20 \pm 0.07$ \\
\hline $33.0(13.00)$ & $4.30 \pm 0.23$ & $1.20 \pm 0.06$ \\
\hline $\begin{array}{l}\text { Bkgd Counting } \\
\text { Rates }\end{array}$ & $0.727 \pm 0.049$ & $0.278 \pm 0.026$ \\
\hline $\begin{array}{l}\text { Calibration Relative to } \\
\text { Models A-1, A-2, and A-3 } \\
\text { (11.4-cm diam) }\end{array}$ & $0.847 \pm 0.039$ & $0.821 \pm 0.041$ \\
\hline
\end{tabular}

has not been developed. Thus, the borehole diameter must be known as a function of depth to use the calibration curves shown in Fig. 11 to interpret the uranium logging data. This situation can be remedied by

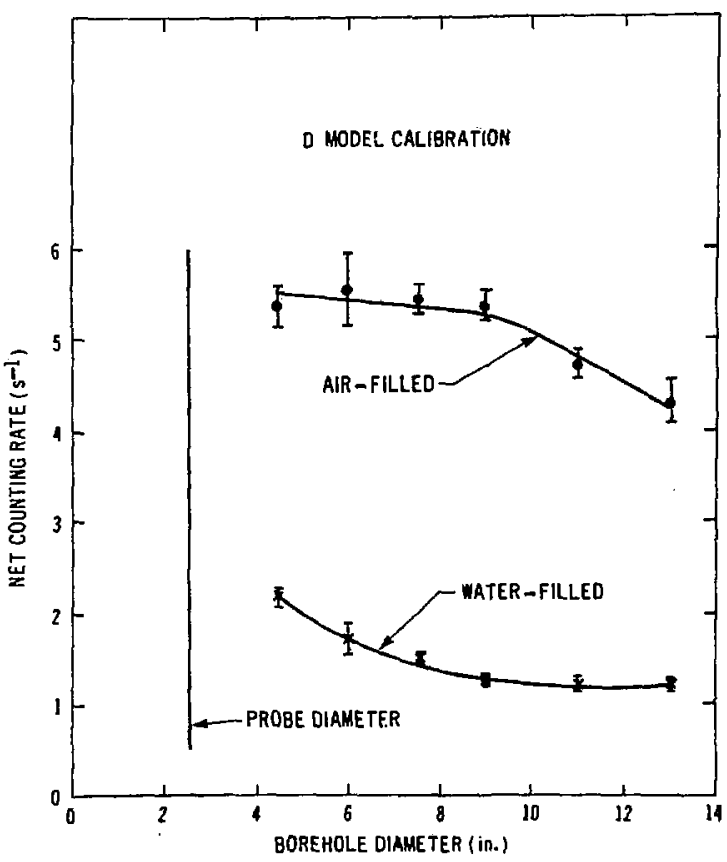

Fiz. 11. Response of the photonewtron-baned uranium well-loging probe to variations in boekhole diameter and fuid. using a separate caliper probe or by incorporating a caliper into an advanced photoneutron probe design.

The response per unit ore grade for the D Model, as determined in the 11.4-cm-diam borehole ( $4.5 \mathrm{in}$.) Fig. 10, is $\sim 15-20 \%$ lower than that obtained in the $A$ models. Including the estimated effect of the porosity difference between the $A$ and $D$ models increases the discrepancy a few per cent. An additional static scan was obtained in the $15.2 \mathrm{~cm}$-diam $\mathrm{D}$ model borehole $(6.0 \mathrm{in}$.) to determine the response of the probe to an ore zone partially below the water table. To simulate this condition the borehole was filled with water to a depth of $\sim 3.3 \mathrm{~m}(10.8 \mathrm{ft})$ and measurements were taken at $7.6 \cdot \mathrm{cm}$ intervals ( $3 \mathrm{in}$.) across the air-water interface. The data, shown in Fig. 12, were all obtained at depths well withir the ore zone of the model.

At $3.50 \mathrm{~m}$ (11.5 ft) the counting rate obtained corresponds to the source-detector region of the probe being totally immersed in water. As the probe is winched up out of the water, the counting rate increases, reaches a maximum at a depth of $3.20 \mathrm{~m}(10.5 \mathrm{ft})$, and slowly returns to the value expected for an air-filled borehole at a depth of $2.8 \mathrm{~m}(9.25 \mathrm{ft})$. This "overshoot" phenomenon is due to the neutron reflection properties of the borehole water. When the photoneutron source is just above the surface of the borehole water, many source neutrons, which are essentially headed in the "wrong" direction (down), are reflected upward toward the general vicinity of the fast-neutron detector. These source neutrons are 


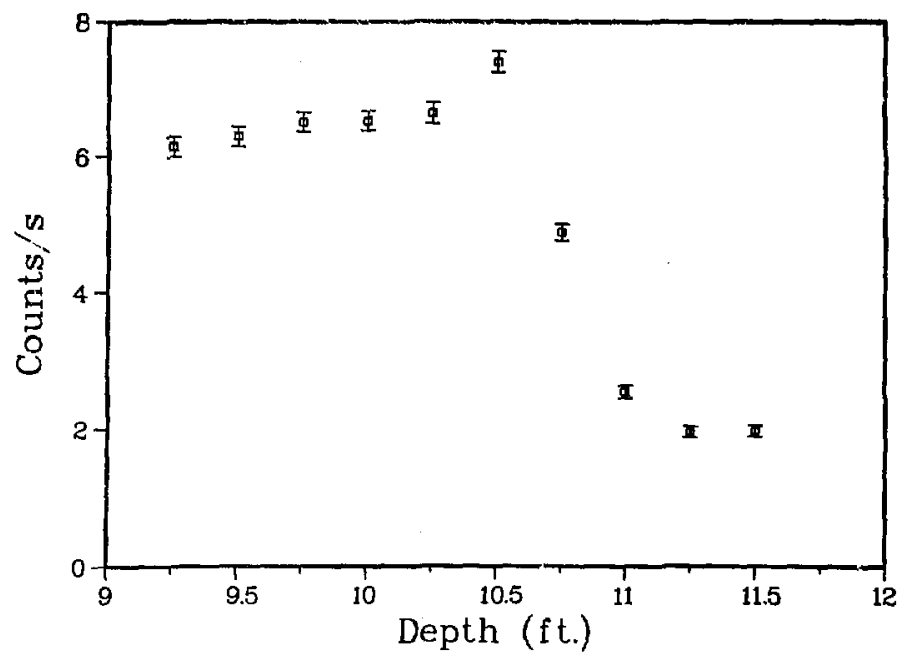

Fig. 12. Response of the photoneutron-based logging probe obtained in the $15.2-\mathrm{cm}$ diam borehole ( $6 \mathrm{in.}$ ) of the $\mathrm{D}$ model with the ore zone partially covered with water.

now capable of inducing fissions in locations that are geometrically more favorable for fast-neutron detection. Thus, the measured counting rate is somewhat enhanced relative to that obtained in an air-filled borehole.

\section{E. Summary}

Static and dynamic uranivin logs were obtained in the $A$ and $D$ models over a period of approximately 10 days. There were no probe failus es of any kind. However, the probe housing was opened to exchange detectors for additional water-factor moasurements. The probe again functioned properly following reassembly. Data obtained at Grand Junction served to calibrate the probe, to determine the effects of borehole diameter and fluid, and to assess the impact of certain formation parameter changes. During the Grand Junction field trip, the photoneutron probe demonstrated adequate durability in the field and sufficient sensitivity to uranium to function at competitive logging speeds. The calibration is linear up to at least $2500 \mathrm{ppm} \mathrm{U}_{3} \mathrm{O}_{3}$ and has a sensitivity of about $80(35)$ counts/s-per cent $\mathrm{U}_{3} \mathrm{O}_{\mathrm{a}}$ for air (water)-filled 11.4 $\mathrm{cm}$ boreholes ( $4.5 \mathrm{in}$.). The detectability limit of the probe is $\sim 40 \mathrm{ppm}(3 \sigma)$ in 100 -s counting time in a 11.4 $\mathrm{cm}$-diam air-filled borehole ( $4.5 \mathrm{in}$.): The probe response is reduced significantly by the presence of substantial quantities of neutron poisons in the formation but has only a weak dependence on formation porosity.

\section{FIELD TESTS}

\section{A. Preparation and Calibration}

The next step in determining the practicality of the Los Alamos photoneutron probe was a test under realistic field conditions. To this end, a logging truck was borrowed from the BFEC Grand Junction facility and outfitted by Los Alamos personnel. The logging truck came equipped with an ac generator and a winch containing $4 \mathrm{HO}$ logging cable. A system for safely transporting the shielding cask containing the antimony source over long distances on public highways and from one borehole to the next was designed and fabricated at Los Alamos. This system in conjunction with a bumpermounted crane was also capable of positioning the cask over the boreholes. The uphole electronics and a complete minicomputer-based MCA were installed in the truck for data acquisition, storage, and display. More detailed information on outfitting the logging truck is in App. C. 
A key safety consideration for actual field use of the photoneutron probe is the possibility that the probe, containing a several-curie ${ }^{124} \mathrm{Sb}$ source, might besome irretrievibly lodged in a borehole. This had not been a major problem previously because of the smooth-walied nature of all the calibration boreholes logged. To minimize the possibility of lodging the photoneutron probe, another probe of similar dimensions and weight but containing no antimony source was fabricated and always used for the first scan of a new borehole. This probe contained a $5-\mathrm{cm}$-diam by $5-\mathrm{cm}$-long Nal detector ( 2 by 2 in.) to measure passive gamma rays from the formation surrounding the borehole and was used as an aid in the identification of potential uranium ore zones.

In preparation for the field tests, the DOE calibration models near Grants, New Mexico, were logged. A new calibration was required because the antimony source used in the tests/calibration runs at Girand Junction 8 months earlier had been replaced. The photoneutron probe was calibrated in the Grants fission-neutron model, which has a $11.4-\mathrm{cm}$-diam borehole (4.5 in.). This model contains two ore zones of $\sim 200$ and $2400 \mathrm{ppm}$ uranium separated by a barren zone. A dynamic scan of the neutron model filled with water is shown in Fig. 13.
The higher grade zone, shown centered around $5.9 \mathrm{~m}$ $(19.5 \mathrm{ft}$ ) in depth, is reasonably uniform over a region $\sim 1.2 \mathrm{~m}$ (4 ft) thick. This scan was taken at $0.7 \mathrm{~cm} / \mathrm{s}(1.4$ $\mathrm{ft} / \mathrm{min}$ ) with the data being read out every $15 \mathrm{~s}$, corresponding to a trave! of $11 \mathrm{~cm}$. Two static measurements were made at a depth of $6.1 \mathrm{~m}(20 \mathrm{ft})$. The count rates were 2338 and 2321 counts $/ 300$ s with a background rate of 77 counts $/ 300 \mathrm{~s}$ measured at a depth of $4.6 \mathrm{~m}(15 \mathrm{ft})$. The net counting rate in the higher grade zone is, therefore, $7.51 \pm 0.12$ counts/s. The ore grade determined by the rhemical analysis of 15 samples taken from the higher grade zone is $2363 \pm 70 \mathrm{ppm}$ uranium. The uncertainty in the ore-grade assignment (made by BFEC) is the root-mean-square deviation in the results of the 15 samples analyzed. The resulting calibration is 315 $\pm 11 \mathrm{ppm}$ uranium/counts/s. Static measurements in the lower grade zone at a depth of $3.6 \mathrm{~m}(11.9 \mathrm{ft})$ and in the upper barren zone at a depth of $2.0 \mathrm{~m}(6.5 \mathrm{ft})$ yield a net counting rate of $0.540 \pm 0.062$ counts $/ \mathrm{s}$. The chemical analysis of the lower grade zone indicated $198 \pm 30 \mathrm{ppm}$ uranium. These results give a calibration of $367 \pm 70$ $\mathrm{ppm}$ uranium/counts/s. The calibration factors derived from the two ore zones are consistent within the stated uncertainties. Because of the higher precision of the

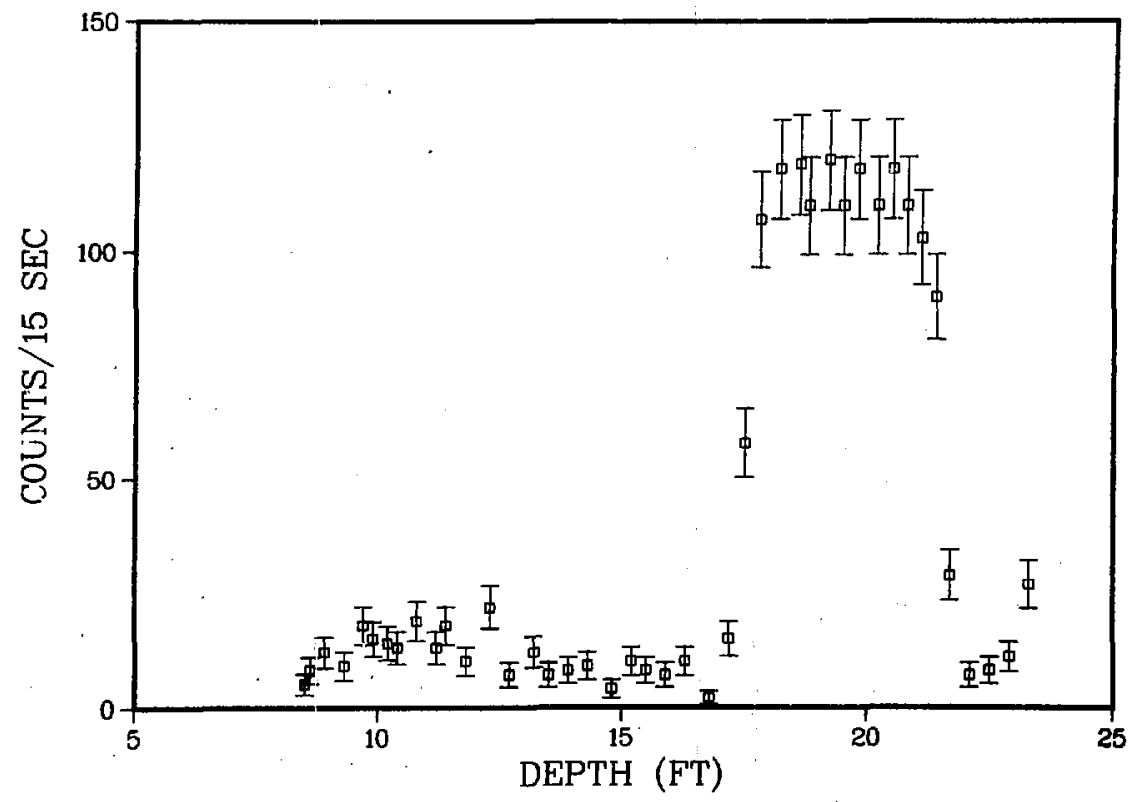

Fiz. 13. Dynamic scan of fission neutron model at Grants, New Mexico, with photoneutron probe. There is a zone of $\sim 200 \mathrm{ppm}$ uranium at $\sim 10 \mathrm{ft}$ separated by a barren zone from a zone of $\sim 2400$ ppm uranium at $\sim 20$ f. 
results from the higher grade zone, that calibration is used for subsequent data analysis.

In addition to the fission neutron model, the Grants facility also includes separate calibration models for potassium, uranium, and thorium. The Los Alamos NaI probe was checked with these models, and approximate stripping coefficients were derived from these data. These enabled the Los Alamos team to gain useful data from the ita. I scans of unknown boreholes to be logged with the photoneutron probe.

The sensitivity of the photoneutron probe to thorium was determined from a thorium zone in one of the calibration boreholes. Counts of $300 \mathrm{~s}$ were taken in the 658-ppm thorium zone and a barren zone $4 \mathrm{ft}(1.22 \mathrm{~m})$ lower. The net count rate resulting from the thorium was measured as $1 \pm 24$ counts $/ 300$ s. Based on this measurement and theoretical considerations, it is highly unlikely that the presence of thorium in a formation would interfere with a uranium log.

\section{B. Logging Site Description}

A very important consideration in choosing a logging site for the field tests was the existence of boreholes with well-characterized uranium-bearing zones. In the summer of 1980 , a site near Cañon City, Colorado, meeting this condition was being explored by Cyprus Exploration Company under the supervision of Fred C. Grigsby, District Geologist. Cyprus Exploration was extremely cooperative and helpful during all of our interactions and provided us with all known borehole data. There were three freshly drilled and cored boreholes that had been logged by a BFEC team using $\mathrm{NaI}$ probes and by IRT Corporation using their delayed fission neutron tool. The BFEC team had also run a caliper probe through the boreholes, which provided borehole diameter information necessary for the precise analysis of the Los Alamos data.

\section{Data Collection}

As mentioned earlier, all boreholes were initially logged with a "mock" probe containing a $\mathrm{NaI}$ detector. The neutron measurements were done in two modes. Initially, a slow, steady dynamic scan at $\sim 2 \mathrm{ft} / \mathrm{min}(0.61$ $\mathrm{m} / \mathrm{min}$ ) was done, often followed by a slower scan of zones of interest. The second mods, which will be referred to as a static scan, consisted of a series of 100 -s counts at fixed positions with 3- to 6-in. spacing ( 7.6 to $15.2 \mathrm{~cm}$ ) through zones of interest. A problem that had never occurred at Los Alamos or at the DOE calibration boreholes near Grants occurred repeatedly, but randomly, at Cãnon City. Bursts of electronic noise entered into the neutron spectrum in such a way that it invalidated the results of that particular measurement. The occurrence of noise was more severe during a dynamic scan, that is, with the winch running; however, noise was also ooserved during static scans. Various attempts to isolate different electrical devices did not seem to help significantly, and because of the intermittent nature of the problem, it was never found and solved. Whenever noise was suspected, the run was repeated. Because the major portion of a dynamic scan is in uranium-free zones, where there are very few real neutron events, noise bursts are generally easy to spot. The comparison of seemingly noise-free runs always indicated good agreement.

The raw count rates obtained had two corrections applied before the Grants calibration could be used. The first correction is straightforward for the decaying ${ }^{124} \mathrm{Sb}$ source strength $(\sim 1 \% /$ day). The second correction is required to compensate for borehole diameters different from the calibration borehole $(11.4 \mathrm{~cm}$ or $4.5 \mathrm{in}$.). This correction was based on caliper information provided by BFEC through Cyprus Exploration Company. Because in all zones of interest the borehole diameter was in the range 11.4-12.7 cm (4.5-5.0 in.), corrections applied were $15 \%$ or less in all cases.

\section{Comparison with Other Techniques}

The gamma logs provided by BFEC through Cyprus Exploration were interpreted using a calibration obtained in Ref. 7. In all but one zone, the gamma-ray log was obtained with a 3.8 - by $7.6-\mathrm{cm} \mathrm{NaI}$ crystal ( 1.5 by $3 \mathrm{in}$.). For zone $1 \mathrm{C}$, data were available only for a 3.8 - by 22.9 $\mathrm{cm}$ crystal ( 1.5 by 9 in.). Thrse data were interpreted using a calibration constant obtained for the larger crystal based on a comparison of the responses of the two detectors for two other uranium-bearing zones in the same borehole.

Dynamic and static scans with the photoneutron probe are plotted together with the BFEC gamma scans for all major uranium-bearing zones in Fig. 14. The ore grade-thickness products in Table $V$ are the areas under 


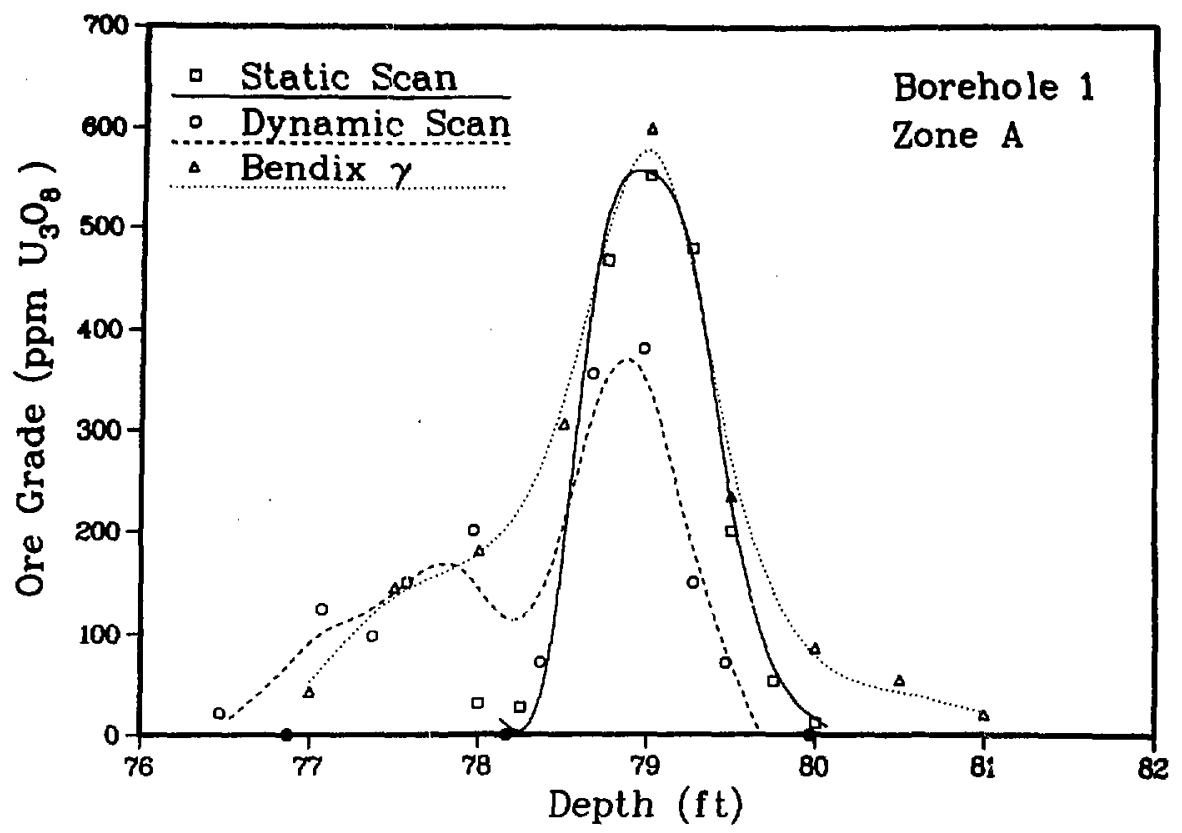

(a)

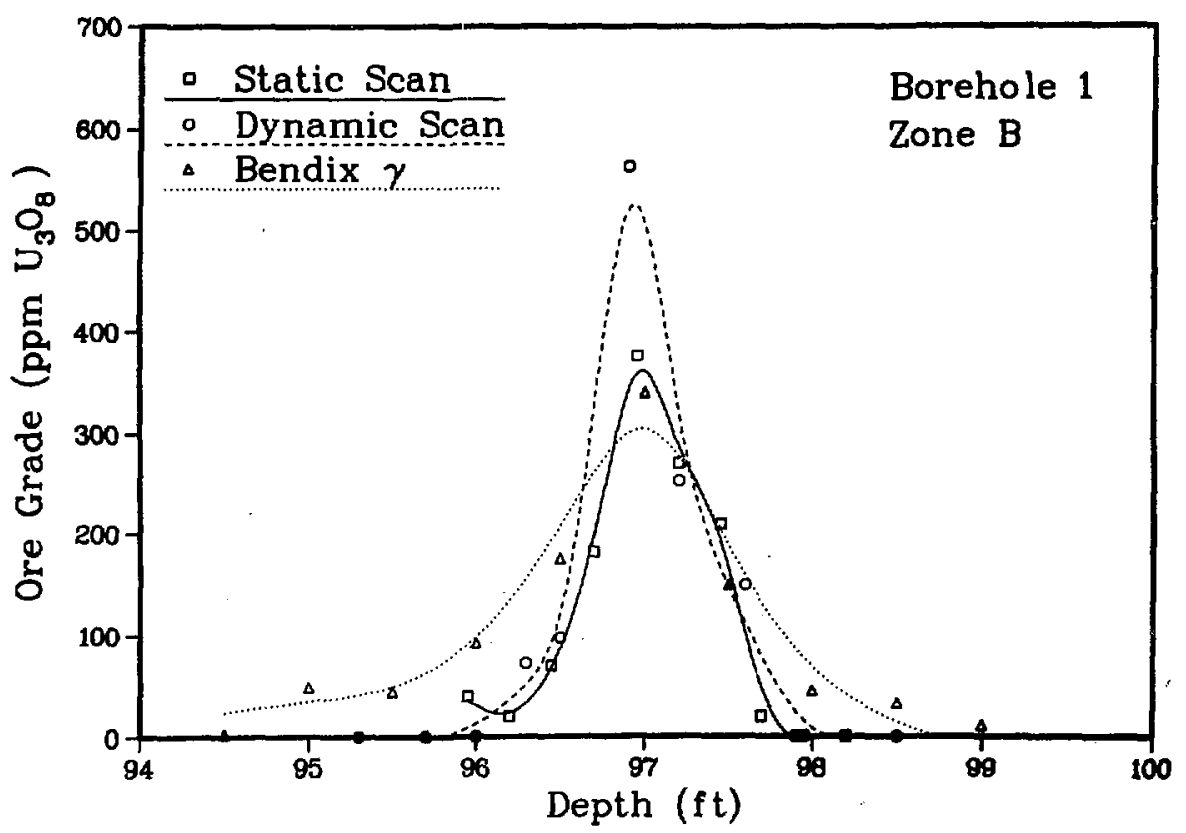

(b)

Fis. 14. Remults of photoneutron probe seans of bereholen near Caition City, Colorado. BFEC Nal sears are inchuded for comparizon. 

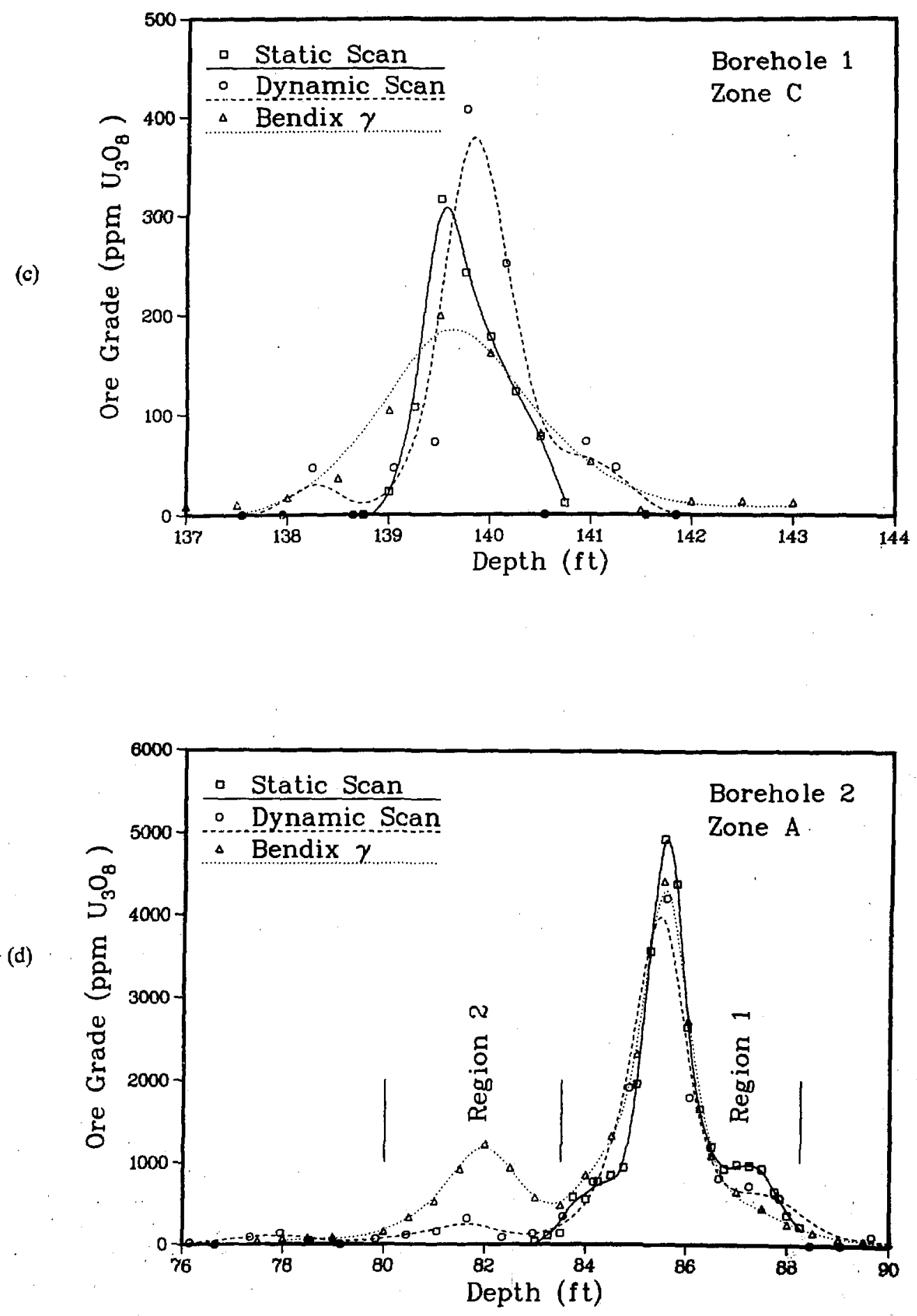


\begin{tabular}{|c|c|c|c|c|c|}
\hline \multirow[b]{2}{*}{ Zone } & \multicolumn{5}{|c|}{ Ore-Grade-Thickness Product (ppm-ft) } \\
\hline & $\begin{array}{c}\text { Static } \\
\text { Neutron }\end{array}$ & $\begin{array}{l}\text { Dynamic } \\
\text { Neutron }\end{array}$ & Gamma & $\begin{array}{l}\text { Core } \\
\text { Chemistry }\end{array}$ & $\begin{array}{c}\text { Core } \\
\text { Gamma }\end{array}$ \\
\hline IA & 511.0 & $320.0(1.2)^{2}$ & 654.0 & 2260.0 & 1785.0 \\
\hline $1 \mathrm{~B}$ & 291.0 & $383.0(1.3)$ & 377.0 & 830.0 & 610.0 \\
\hline IC & 269.0 & $281.0(1.4)$ & 271.0 & $655.0^{\mathrm{b}}$ & $450.0^{b}$ \\
\hline $2 \mathrm{~A}$ & 7269.0 & $6778.0(2.4)$ & 7183.0 & 13795.0 & $\ldots$ \\
\hline 2B & 230.0 & $285.0(2.4)$ & 451.0 & 424.0 & 545.0 \\
\hline $\mathbf{3 A}$ & 262.0 & $470.0(1.0)$ & 393.0 & 475.0 & 330.0 \\
\hline
\end{tabular}

"Numbers in parentheses are dynamic neutron scan speeds ( $\mathrm{ft} / \mathrm{min})$.

'These results are a lower limit only because of incomplete core analyses.

'Gamma analysis of core samples is not available for this zone.

the curves shown in Fig. 14, with the boundaries being determined by the extent of the static neutron scan. The data shown have been shifted in depth by up to $0.61 \mathrm{~m} \mathrm{(2}$ $\mathrm{ft}$ ) to match peak positions. For comparison, Table $\mathrm{V}$ also lists ore-grade-thickness products obtained by core sample analyses (provided to Los Alamos by Cyprus Exploration Company). There are notable differences between the neutron data and core sample data; this is not surprising because the neutron tool interrogates considerably more volume than a narrow core sample. This contention is reinforced by data obtained for BFEC by IRT Corporation using a delayed fission neutron technique based on an isotopic californium source. These data, presented in Fig. 15 and Table VI, dramatically illustrate the degree of disequilibrium often observed in the field. Chemical analysis and closed-can gamma analysis of core samples help to illustrate the nature of the problem and, therefore, the virtue of a direct uranium interrogation such as with the neutron-based tools. The passive gamma-ray analysis of radiations from the daughter products, although simpler to implement, can yield misleading information in a disequilibrated zone, with potentially severe economic impact.

\section{v. CONCLUSIONS AND SUGGESTIONS FOR FURTHER DEVELOPMENT}

\section{A. Conclusions}

Over the last several years, with the support of the NURE program, the photoneutron-based uranium method has progressed from a laboratory feasibility study to a reliable, field-worthy, in situ uranium exploration system. A summary of system properties, described in detail in the main text of the report, is presented in Table VII.

The system gives a direct uranium ore-grade determination and, therefore, eliminates assay ambiguities associated with ore bodies in which the uranium and its daughters are not in equilibrium. Field application of this system at exploration and mining sites should result in a substantial reduction in core drilling and considerable savings in exploration and mining reserve estimation costs.

Of course, the photoneutron-based uranium exploration system is at the prototype stage, and many improvements can be made to enhance its capabilities and efficiency in field operation. We recommend that the present probe undergo further field testing followed by an advanced engineering design using the suggested improvements discussed below.

\section{B. Suggestions for Further Development}

1. Assay Interpretation. As noted in Sec. III, the response to uranium is heavily influenced by conditions such as borehole size and fluid and the presence of neutron poisons. If a caliper $\log$ is run on the borehole or the diameter is known to be uniform, the results shown in Fig. 11 can be used to correct the photoneutron-based assay. Also, in principle, if the presence of neutron poisons is known, the effect on the photoneutron $\log$ can 


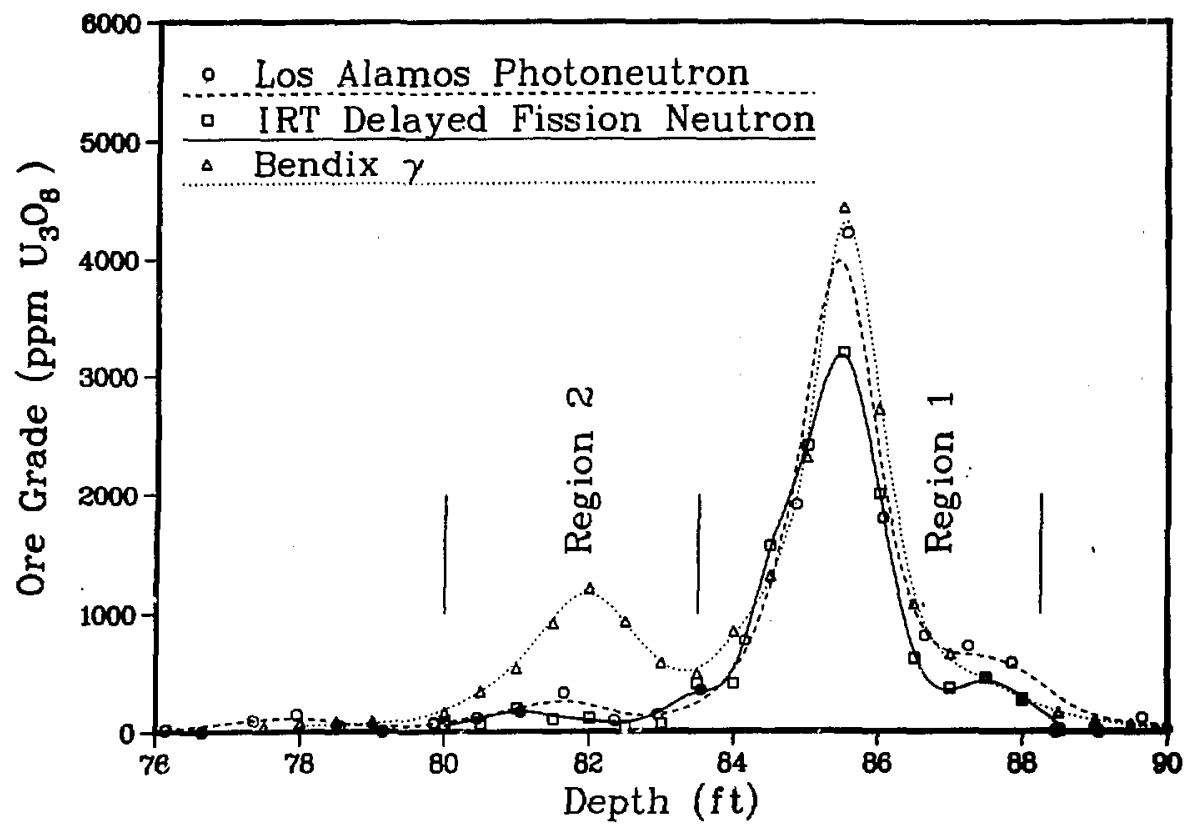

Fig. 15. Comparison of resulis obtained using three difTerent techniques to assay an equilibrated zone (Region 1) and a zone with uranium out of equitibrium with its daughters (Region 2).

\begin{tabular}{|c|c|c|}
\hline \multicolumn{3}{|c|}{$\begin{array}{l}\text { TABLE VI. Comparison of Results of Various Logging Techniques } \\
\text { in a Disequilibrated Zone }\end{array}$} \\
\hline \multirow[b]{2}{*}{ Technique } & \multicolumn{2}{|c|}{$\begin{array}{l}\text { Ore-Grade-Thickness Product } \\
\text { (ppm-ft) }\end{array}$} \\
\hline & $\begin{array}{l}\text { Disequilibrated } \\
\text { (Zone 2) }\end{array}$ & $\begin{array}{l}\text { Equilibrated } \\
\text { (Zone 1) }\end{array}$ \\
\hline Los Alamos dynamic neutron & 618 & 6778 \\
\hline IRT delayed fission neutron & 407 & 5761 \\
\hline Bendix gamma & 2442 & 7183 \\
\hline Core chemistry & 351 & 13795 \\
\hline Core gamma & 1320 & (N/A) \\
\hline
\end{tabular}

be corrected using a series of calibrations obtained in appropriate models.

If a secondary detector could be found to measure the borehole and formation parameters, it would give a more convenient and reliable correction to the photoneutron system data. This correction feature might be applicable as well to other borehole active neutron systems. Los
Alamos has carried out some preliminary investigutions along this line using a ${ }^{3} \mathrm{He}$ detector and a $\mathrm{NaI}$ detector: The ${ }^{3} \mathrm{He}$ detector was briefly field-tested at Grand Junction and found to have a limited dynamic range. There is still a great need for research and development in this area. 
TABLE VII. Summary of Photoneutron Exploration System Features

\begin{tabular}{|c|c|}
\hline Probe size: & $6.7 \mathrm{~cm}(2-5 / 8 \mathrm{in}$.$) diam by 2.3 \mathrm{~m}(7-1 / 2 \mathrm{tt})$ long \\
\hline Response: & $\begin{array}{l}80 \text { counts } / \mathrm{s}-\% \mathrm{U}_{3} \mathrm{O}_{2} \text { (linear from } \\
0 \text { to } \sim 2500 \mathrm{ppm} \text { ) }\end{array}$ \\
\hline Background: & $\begin{array}{l}75 \text { ppm } \mathrm{U}_{3} \mathrm{O}_{8} \text { (source related) } \\
1 \mathrm{ppm} \mathrm{U}_{3} \mathrm{O}_{8} \text { (passive) }\end{array}$ \\
\hline Detection limit: & $40 \mathrm{ppm}$ in $100 \mathrm{~s}(3 \sigma)$ \\
\hline Neutron source: & ${ }^{124} \mathrm{Sb}-\mathrm{Be}\left(24 \mathrm{keV}, \mathrm{T}_{1 / 2}=60\right.$ days $)$ \\
\hline Uranium signature: & Prompt fission neutrons \\
\hline Detector type: & $18 \mathrm{~atm}^{4} \mathrm{He}$ \\
\hline Borehole water effects: & $\begin{array}{l}\text { Signal reduction of } \sim 2.5 \text { for water-filled } \\
11.4-\mathrm{cm}(4-1 / 2 \text { in.) borehole (compared to air-filled) }\end{array}$ \\
\hline
\end{tabular}

2. Radioactive Source. The must beneficial improvement to the whole system would be the use of a neutron source, of similar energy to the $\mathrm{Sb}-\mathrm{Be}$ source, with a greatly reduced gamma-ray flux, thus allowing implementation of a more efficient neutron detector. ${ }^{9}$ This combination would permit faster logging speeds and probably result in improved sensitivity. A neutron source of superior strength, size, half-life, and cost has not yet been identified. ${ }^{10}$ The use of a longer lived photoneutron source would also be a major improvement to the uranium well-logging system. Yttrium-88 $\left(\mathrm{T}_{1 / 2}=107\right.$ days) was tested in the laboratory as an alternative to ${ }^{124} \mathrm{Sb}$ (Refs. 11 and 12). Although this acceleratorproduced isotope has a longer useful life, the effective ore-grade sensitivity is also reduced relative to the present system.

3. Probe and Cask. Both the mechanical and electrical design of the probe could be simplified if the present ability to turn the neutron production on and off were foregone. There is no practical advantage in uranium logging in having a neutron on/off switch, because biological shielding considerations are dominated by the gamma radiation from the photoneutron source.

As shown in Fig. 16, a design with the ${ }^{124} \mathrm{Sb}$ source fixed in the beryllium converter would allow the probe and the cask to be substantially shorter. There would be considerable savings in weight by reducing the length of the cask, although some of the gain would be lost as a result of the need for additional neutron shielding. The design illustrated in Fig. 16 would result in a probe $1.3 \mathrm{~m}$ (4.4 ft) long with a total probe and cask weight of $400 \mathrm{~kg}$

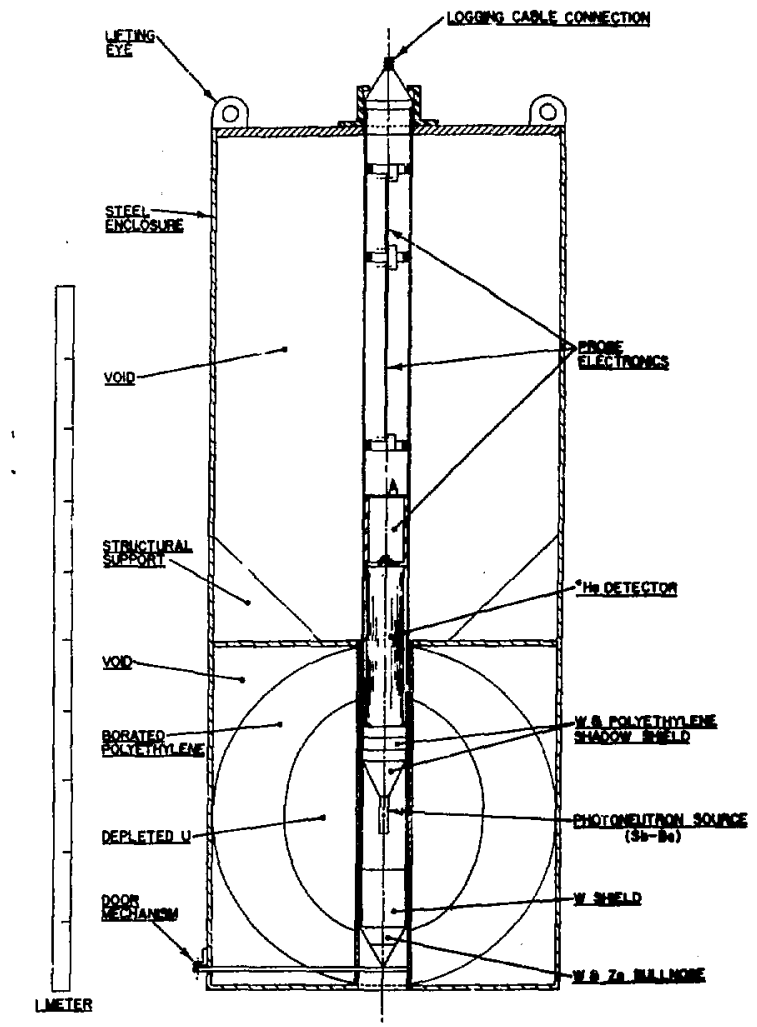

Fig. 16. Advenced design for a shorter photoneutron-based probe in which the ${ }^{124} \mathrm{Sb}$ gamma-ray source remains fixed in the bery photoneutron converter. 
(900 lb). The major changes called for in the revised cask design are the addition of borated polyethylene around the perimeter to shield the photoncutrons and an ellipsoidal shape for the depleted uranium gamma-ray shield to minimize the weight. Even in the present design, the thickness of the cask could be reduced for a reduction in weight while maintaining a reasonable dose rate.

A considerable savings of effort during logging operations might be effected if, during routine logging, the entire probe and cask could be handled as a single unit. The electronics end of the probe would be decoupled from the source end only for maintenance of the electronics/detector or replacement of the radioactive source. This would also eliminate the need for a cask lid, except during the unusual circumstance when the probe halves are decoupled. Another modification that would improve the system would be the development of a "downhole" multichannel analyzer. Although the probe would ultimately have to be longer, the calibration would be independent of cable length.

A lighter lid could be fabricated, for the current system, if a minor change were made in the alarm system. There is a microswitch on the top of the cask to sound an alarm if the probe is too near to ground level with neutron production still enabled. The entire lid has been made thicker so that the material around the recess in the lid that accommodates the microswitch provides adequate shielding. By relocating the microswitch to the leveling plate, the entire lid could be made thinner and simpler to fabricate.

\section{ACKNOWLEDGMENTS}

The authors appreciate the technical support received from many members of the Safeguards Assay group during the fabrication, assembly, and testing of the photoneutron-based uranium exploration system. The mechanical design of the probe and cask was completed by L. G. Speir and G. Walton in an efficient and timely manner. H. R. Dye was essential to the probe and cask fabrication and assembly effort, and D. C. Garcia and R. L. Brewer were largely responsible for outfitting the logging vehicle. The electronics design, fabrication, and testing tasks were supervised by R. Slice. R. Kuoppala made a strong contribution to this effort as well as the electronic aspects of outfitting the logging vehicle. S. Beach and C. Spirio assisted with planning and coordination and H. R, Dye, R. Kuoppala, and R. L. Brewer provided field technical support.

The efforts of C. Koizumi, M. Dale, and R. Wilson of Bendix Field Engineering Corporation (BFEC) and L. Ball and F. Dodd of the US Department of Energy in coordinating the calibration field trip at Grand Junction were crucial to the success of these important tests. In addition, J. Duray and C. Koizumi (BFEC) provided timely assistance in identifying an appropriate logging vehicle and site for the Colorado field tests.

We gratefully acknowledge the cooperation of Cyprus Exploration Company in allowing access to their exploratory boreholes and associated documentation.

\section{APPENDIX A}

\section{DETAILED PROBE DESCRIPTION}

\section{PROBE DESIGN}

\section{A. Mechanical}

1. Source Drive Unit. As detailed in Fig. A-1, the lower section of the photoneutron probe contains the source drive-motor, coupling, lead screw, microswitches, ball nut, and associated push rods connected to the ${ }^{124} \mathrm{Sb}$ source capsule. Normally, this lower section remains inside the gamma-ray shield except when it is being used for logging. As discussed below, during transport, a shielding lid is bolted onto the cask, completely enclosing and sealing the source-drive section.

The pressure housing (1) of the photoneutron probe is constructed from $6.7-\mathrm{cm}-0 . d$. (2.625 in.), $0.30-\mathrm{cm}$-wall ( 0.120 in.) stainless steel and is designed for a maximum operational pressure of 2000 PSIG. Access to the inside of the pressure housing is sealed by double $O$ rings. The 


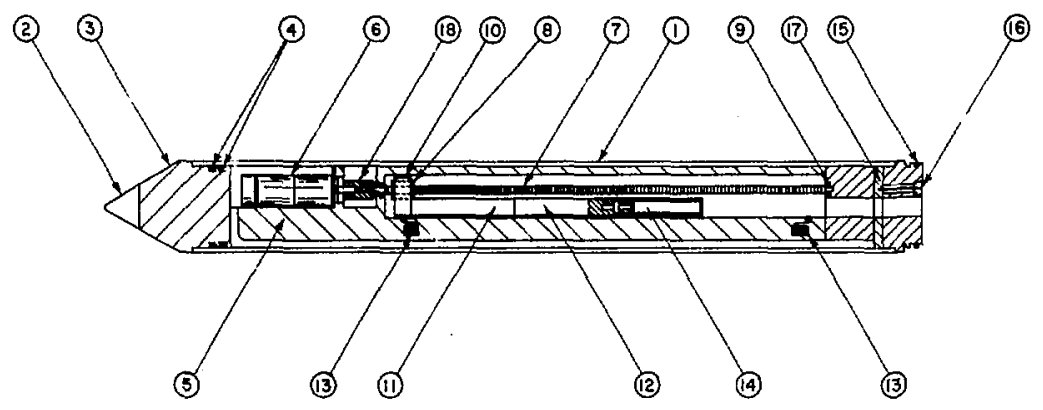

Fig- A-1. Source-drive unit contuined in lower probe section.

probe tip (2) is fabricated from zinc, and is intended to protect the probe from galvanic corrosion during prolonged immersion in water- or mud-filled boreholes.

The probe bull-nose (3) material is tungsten alloy to provide additional gamma-ray shielding at the cask bottom opening. Two neoprene $O$ rings (4) seal the probe between the bull nose and pressure housing.

All interior structural members (5) are fabricated from tungsten alloy to constrain radiation streaming toward the top of the source-drive channel, from the $\mathrm{Sb}$ source, to a narrow cone. These parts all bolt together into a monolithic base for attachment of the source-drive mechanism.

The source-drive motor (6) is a $50-\mathrm{V}$-dc, permanent magnet, shielded, planetary-gear motor. The nominal speed is $9500 \mathrm{rpm}$ through a $22: 1$ reduction gear for an output of $431 \mathrm{rpm}$ to the lead screw (7). This speed allows full travel of the source from the storage position to the photoneutron production position in $\sim 25 \mathrm{~s}$. The motor and lead screw are connected by a solid coupling (18). The lead screw (7) is a stainless steel, 0.48 -cm-diam ( 0.188 in.) by $0.16-\mathrm{cm}$-pitch $(0.063$ in.), recirculating-ball type with ball nut (8). Lead-screw support is provided by ball bearings (9) at each end. The ball nut is captive inside an attachment bridle (10), which in turn supports the source push rods (11) and (12). The lower section of the push rod (11) is stainless steel, and the section nearest the source (12) is tungsten alloy. This tungsten section is threaded to receive the end plug of the source capsule. Source position is indicated at top and bottom limits by microswitches (13).

The gamma-ray source capsule (14) is filled with $\sim 24$ $g$ of antimony. The capsule body and end plug are machined from E-Brite* stainless steel, a material with low cobalt content used to minimize the production of radioactive ${ }^{60} \mathrm{Co}$ during the reactor activation of the antimony. The overall length of the capsule is $6.6 \mathrm{~cm}(2.6$ in.), and the wall thickness of the body is $1.6 \mathrm{~mm}(0.063$ in.). ${ }^{13}$

The probe coupling piece (15) provides mechanical attachment and 0-ring sealing surfaces for the upper half of the probe. Six electrical feed-throughs (16) are provided in the coupling for motor power and sourceposition information. A resilient foam piece (17) provides insulation and strain relief for the six wires connected to the feed-throughs.

2. Probe Physics and Electrical Section. The upper section of the photoneutron probe (Fig. A-2) contains the beryllium for photoneutron production; the proportional counter for fast-neutron detection with its gamma-ray shielding and high-voltage junction box; and the electronics, composed of printed circuit boards, bulkheads, and clamshell tubing. The female coupling ring (1) and body (2) provide mechanical and electrical connection between the upper and lower sections of the probe. The stainless-steel ring and mating coupling piece (Fig. A-1) are machined with a $10^{\circ}$ modified square thread at 12 thds/in. to facilitate assembly in the field. The coupling body contains two $O$ rings (3) in captive dovetail grooves and six electrical feed-throughs (4). The feed-through conductors are spring-loaded to positively engage the mating conductors in the source-drive section of the

*E-Brite is the trade name for a stainless steel manufactured by Allegheıy Ludlum Steel Corporation, Oliver Building, Pittsburgh, PA 15222. The American Society of Metals designation is $26-1$. 


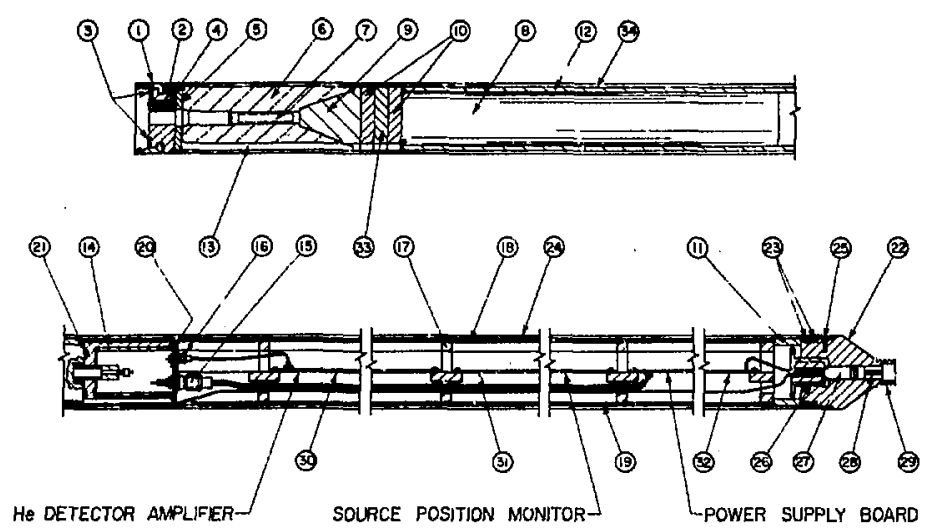

Fig. A-2. Scale drawing of photoneutron production, fission neutron detection, and electronics sections of uranium well-logging probe.

probe. A resilient foam piece (5) provides insulation and strain relief for the six feed-through wires.

The ${ }^{124} \mathrm{Sb}$ gamma-ray source capsule (7) is shown in the interrogation position, i.e., inserted in the beryllium sleeve (6). In this position, photoneutrons are produced by interaction of the ${ }^{124} \mathrm{Sb}$ gamma rays and the beryllium nuclei. When the ${ }^{124} \mathrm{Sb}$ source capsule is retracted to the storage position in the lower section of the probe, the production of photoneutrons is negligible.

The $5.08-\mathrm{cm}$-diam by $30.5-\mathrm{cm}$-active length $(2.00$ by 12 in.), 18-atm helium recoil proportional counter* (8) used for detection of neutrons from uranium fission is shielded from the direct gamma radiation of the ${ }^{124} \mathrm{Sb}$ source by a tungsten alloy cone (9), two tungsten alloy disks (10), and a high-density polyethylene disk (33). The gamma-ray shielding may be reduced by removing one or all of the disks $(10,33)$ with the change in length compensated by the replacement of the plastic spacer (11). Radial shielding from scattered gamma radiation is provided for the detector (8) by an annular piece of highdensity $\left(\rho=18.6 \mathrm{~g} / \mathrm{cm}^{3}\right.$ ) tungsten alloy (12). Background in the detector produced by thermal neutron interactions with ${ }^{3} \mathrm{He}$ is suppressed by wrapping the tungsten annulus and detector ends with 0.4 -mm-thick cadmium sheet (0.017 in.) (34).

The "HN"-type electrical connector supplied with the detector has been replaced by a threaded spud integral

*Reuter Stokes, 18530 South Miles Parkway, Cleveland, $\mathrm{OH}$ 44128. with the high-voltage junction box (14). The junction box is hermetically sealed by an $O$ ring (21) and rubber gasket (20). Isolation of the typical operating potential of $\sim 1900 \mathrm{~V}$ is achieved with an inside liner of plastic. The high-voltage (15) and signal (16) connectors both attach to the junction-box cover. The junction box (14); printed circuit (P.C.) boards (30), (31), (32); and associated bulkheads (17) are constrained by two clamshell tubes (18) and (19). This ensures a rigid assembly that protects electronic components during insertion into the probe pressure housing (24). An $0.95-\mathrm{cm}$-wide wire-way channel (0.375 in.) (i3) traverses the full length of pieces (6), (9), (10), (33), (12), and (14). This channel provides clearance for the conductors necessary for motor power and source-position information to pass from the lower section of the probe to the P.C. boards (30), (31), and (32).

The probe end piece (22) serves to seal the probe, to provide electrical connection to the logging cable, and to lift the probe. A double O-ring seal (23), similar to that at the bottom of the probe, allows operation at the design pressure. The end plug (22) is secured inside the pressure housing (24) by four screw heads (25). Screwed inte the end plug is the brass assembly (26), which maintains the electrical connector (27) under compression and in register with the keyway (28). The threaded end (29) is 2.22-cm-diam ( 0.875 in.) by 12-thread stub acme, made 
compatible with a standard four-conductor, $2.54-\mathrm{cm}$ diam, cable-head assembly (1 in.)."

\section{B. Electrical}

1. General Description. The photoneutron probe electrical system is designed for compatibility with existing well-logging vehicles. Typically, such vehicles are equipped with a winch and armored cable used to mechanically raise and lower the probe in a borehole and to transmit electrical power and signals between the probe and the surface. The armored cable most often encountered in the uranium well-logging industry has four conductors interwoven inside a steel jacket (Rochester Corp., Model 4HO).** Compatibility with the $4 \mathrm{HO}$ logging cable requires an electronics design that makes optimal use of the small number of available conductors.

The electrical system of the photoneutron probe is composed of downhole components that reside on P.C. boards inside the pressure housing and uphole components designed to be mounted in the logging vehicle (Fig. A-3). The electrical system has two major functions: (1) processing of the helium proportional counter signals and (2) moving and monitoring the position of the ${ }^{124} \mathrm{Sb}$ source.

2. Detector and Amplifier Circuit. The detector and amplifier circuit (30) is located on the P.C. board adjacent to the high-voltage junction box (14) (Fig. A-2). The detector bias is conveyed to the junction box by an SHV connector (15). The signal from the detector is coupled out of the junction box to a preamplifier through a short microdot cable and connector (16). Charge collected in the detector is converted to a unipolar voltage by the preamplifier (LeCroy Model TRA510). $\dagger$ Undershoot produced by the exponential decay of the preamplifier output is canceled by a pole-zero network. This voltage pulse is then differentiated and shaped into a quasi-Gaussian pulse. The differentiation suppresses the pulse heights of the longer rise-time, gamma-ray events

-Gearhart Industries, P. O. Box 1936, Fort Worth, TX 76101. * Rochester Corporation, Division of Ramtech Industries, P. O. Box 312, Culpeper, VA 22701.

†LeCroy Research Systems Corporation, 700 South Main Street, Spring Valley, NY 10977. relative to the neutron events, and thus enhances the efficiency for detecting fast neutrons. The pulse shaping is accomplished using an active network and serves to improve the electronic signal-to-noise ratio.

The signal is then amplified and differentially coupled to two of the logging cable conductors by a transformer. After traversing the length of the cable, the signal is differentially coupled through the winch slip rings at the logging vehicle through a transforner. The signal is then passed to the differential inputs of an Ortec $450^{*}$ amplifier, where it is again shaped and amplified. The output is then sent to an on-board, computer-based multichannel analyzer, where it is digitized and the resulting pulse-height spectrum dumped to a permanent storage medium.

3. Source-Position Control and Monitor. The ${ }^{124} \mathrm{Sb}$ gamma-ray source is moved from the storage position in the probe to the interrogation position using a $50-\mathrm{V}$-dc motor to drive a lead screw. The current to operate this motor is delivered by one of the logging cable conductors and the armored jacket. The direction of the source movement can be reversed by reversing the polarity of the current through the motor, i.e., by reversing the polarity of the voltage applied between the motor-control conductor and the armored shield.

The motor drives the source up to the end of its travel in either direction and stalls. (The stall current at $50 \mathrm{~V}$ is $250 \mathrm{~mA}$.) The motor has been left energized in the stalled condition for extended periods of time ( $\geq 30 \mathrm{~min}$ ) without any ill effects.

Microswitches at each end of the travel of the gammaray source are used to monitor the source position. The source-position monitor circuit is located on the second P.C. board and has as its major components two sinewave osciliators with frequencies of $\sim 12$ and $32 \mathrm{kHz}$, respectively. The oscillator outputs are coupled through solid-state gates to a summing amplifier and then pass to the conductor, which powers the source-position motor.

When the source is at one extreme of its travel, the corresponding microswitch closes and enables the gate to transmit one of the two frequencies to the logging vehicle at the surface. If the source is at the other extreme, the other microswitch closes and the second frequency is

"EG\&G Ortec, 100 Midland Road, Oak Ridge, TN 37830. 


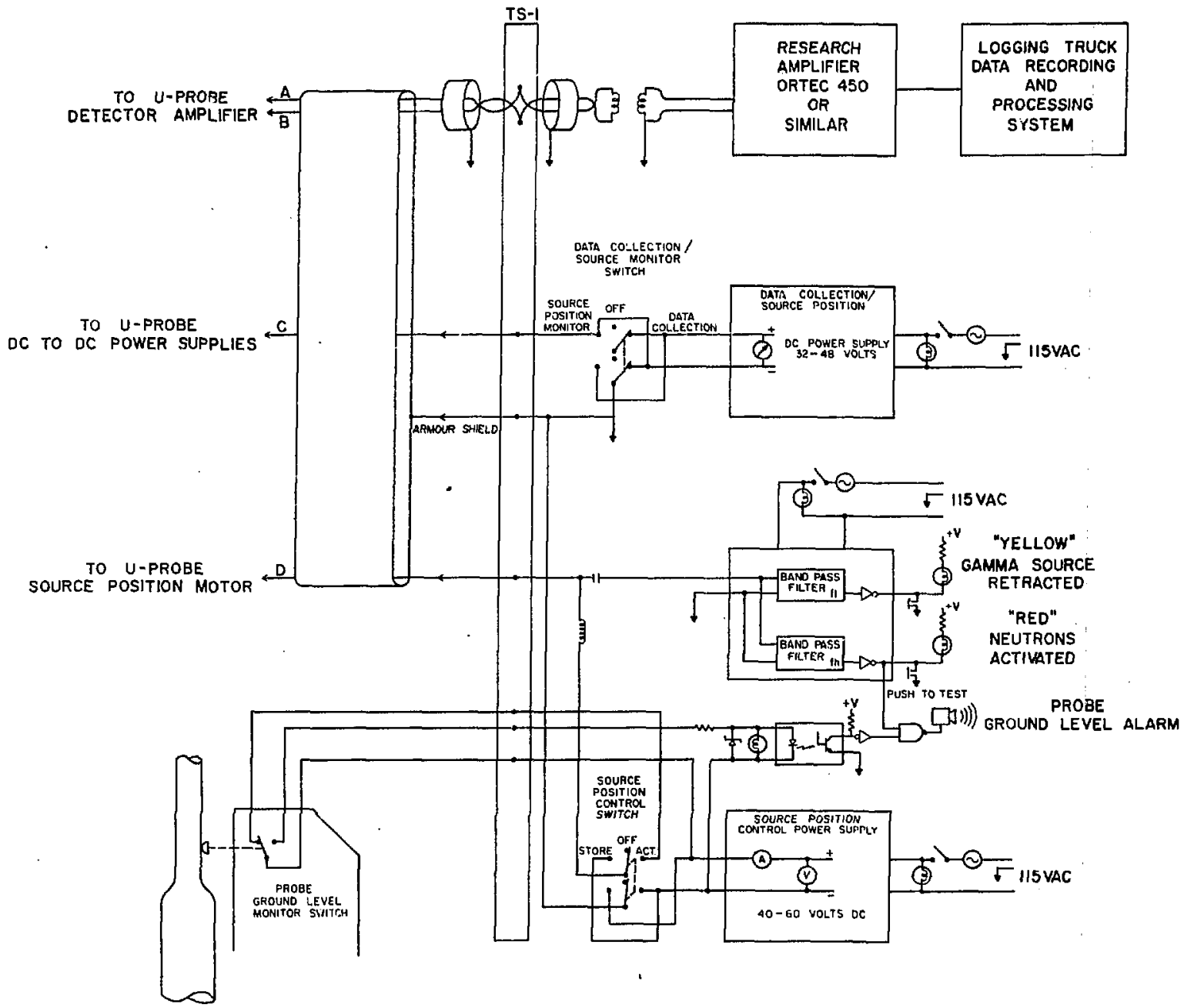

Fig. A-3. Probe electronics components.

transmitted. Neither frequency is transmitted if the source is positioned between the extreme ends of its travel.

4. Power Supply Circuit. The helium recoil proportional counter bias of $\sim 1900 \mathrm{~V}$ is supplied by one dc-todc converter, and the $\pm 12 \mathrm{~V}$ required by the probe electronics components are provided by a second dc-todc converter located on the same circuit board. The voltage to operate these dc-to-dc converters is delivered through one of the logging cabie conductors and the armored shield. A regulator maintains the voltage at the input to the dc-to-dc converters at $28 \mathrm{~V}$. The voltage required at the surface to operate the regulator is a function of the cable length and type, but typically will fall in the range of 35-50 V.

5. Uphole Electronics System. The uphole part of the elentronics system consists of an interlock switch mounted on the source storage container, a data collection-source control and monitoring chassis, and a NIMcompatible research amplifier (Fig. C-3 in App. C).

The data collection-source control and monitoring circuits are powered by $110 \mathrm{~V}$ ac and are mounted in a standard $48-\mathrm{cm}$ rack chassis (19 in.) with a $22-\mathrm{cm}$ panel height (8.75 in.). The source-control circuit is powered 
by a dc supply with a variac-controlled, full-wave bridge rectifier and front-panel-mounted current and voltage monitor meters. The direction of the source drive motor is controlled by a front-panel, polarity-reversing switch with a center "off" position.

The data collection-source monitor power supply circuit consists of a variac-controlled, full-wave bridge rectifier with a voltage monitor meter on the front panel. Data collection mode or source-position monitoring mode is selected by reversing the polarity of the powersupply voltage with a switch with a center "off' position. The three-position mode switch is connected to a relay controlled by an interlock switch located near the top of the storage cask. If the cask interlock switch indicates that the probe is above ground level, the relay overrides the mode-selection panel switch and selects the sourceposition monitor mode.

In the source-position monitoring mode, the polarity of the voltage between the logging-cable electronics power conductor and the armored shield is negative. $\mathbf{A}$ relay is activated by this negative polarity and applies the output voltage of the $\pm 12-\mathrm{V}$ dc-to-dc converter to the source-monitor electronics. A blocking diode prevents the detector high-voltage dc-to-dc converter from operating during this time.

After the source has been positioned and its location verified, the polarity of the voltage applied between the logging-cable electronics power conductor and the armored shield is switched to positive. The detector highvoltage dc-to-dc converter is now allowed to operate. A blocking diode prevents a relay from actuating and the $\pm 12 \mathrm{~V}$ from the dc-to-dc converter is applied to the datacollection electronics and removed from the sourceposition monitor electronics.

The source-position monitor circuit consists of logic devices, two band-pass filters, three LED indicator lights, an audio alarm, and associated power supplies. Signals (ac) from the source-position oscillators are passed from the source drive-motor power line to the band-pass filters through a blocking capacitor. Storage and interrogation source positions are indicated by the reception of signals with frequencies of $\sim 12$ and $32 \mathrm{kHz}$, respectively. The band-pass filters separate these signals and route them to logic circuits, which activate the appropriate LEDs on the front panel of the chassis. An audio alarm, mounted on the front panel, is activated when the cask interlock switch indicates that the probe is above ground level and the source is not in the stored position.

\section{SOURCE STORAGE CONTAINER}

In order to minimize source handling in the field, a source container design has been selected that incorporates shipping, storage, and well-logging functions in a single unit. The major design criteria are that the container provide adequate biological shielding of the ${ }^{124} \mathrm{Sb}$ gamma radiation and assurance that the source will be retained within the container during the operations described above. Department of Transportation (DOT) regulations governing the shipping of radioactive materials largely determine the detailed methods by which the design criteria are met.

\section{A. DOT Requirements}

In meeting these DOT regulations, the ${ }^{124} \mathrm{Sb}$ capsule was declared to be in "Special Form" on the basis of calculations and/or tests. For this declaration to be valid, the source capsule must present little hazard because of radiotoxicity and little possibility of contamination if released from the shielding container. The criteria for determining the validity of the Special Form declaration are a series of physical calculations and/or tests on the source capsule. These tests include a 30 - $\mathrm{ft}$ free drop, percussion, heating in air, and immersion in water.

Qualification of the source capsule as Special Form allows Type A packaging for the shielding container. The regulations for Type $A$ are less stringent than would be specified if the source capsule were not in Special Form. Again, qualification for Type A packaging is determined on the basis of the results of a series of physical calculations and/or tests. These tests include heat, cold, reduced pressure, vibration, water spray, 4-ft free drop, 1- $\mathrm{ft}$ corner drop, penetration, and compression. These calculations and/or tests were conducted in collaboration with the Engineering Analysis Group at Los Alamos.'

In addition to these requirements, there are guidelines for securing the source capsule in the container, securing the container to the transport vehicle, labeling, surface contamination, tamper sealing, and surface radiation 
dose. All of these items have been considered in the design that was ultimately derived and is shown in Figs. 3 and C-1 (App. C).

\section{B. Mechanical Design}

The cask is a two-part design with the body serving as the source storage area and the cap providing the shielding closure for shipment. Both pieces are fabricated largely from depleted uranium to obtain adequate gamma-ray shielding in minimal space at reasonable cost. The gamma-ray source is normally stored in the upper region of the body, which contains sufficient (11.4 $\mathrm{cm}, 4.5 \mathrm{in}$. uranium) shielding to reduce the dose at the surface to less than $10 \mathrm{mrem} / \mathrm{h}$. The lower region of the body was constructed with less shielding because the gamma-ray source only traverses this region on its way into and out of the borehole.

The body of the cask is constructed with large corner radii and fillets to reduce the potential stress in these areas and to ensure containment of the source if the cask is accidentally dropped. The depleted-uranium body is covered with an $0.95 \mathrm{~cm}$ stainless steel can $(0.375 \mathrm{in}$.) that increases the overall strength of the cask assembly. In addition, the can serves as a biological shield from the intrinsic short-range beta radiation emanating from the depleted uranium and contains any removable contamination from the body surface. The base of the body is lined with an $0.32-\mathrm{cm}$ stainless steel sleeve $(0.125 \mathrm{in}$.) joining the top and bottom end plates. The lower body is retained in the can with a ring welded to the bottom plate. The bottom of the can is covered with a 1-in.-thick steel plate, which includes a retractable sliding door. A padlock and two recessed, socket-head cap screws secure the door in position during shipment and storage. The screws are not accessible when the cask is seated, thus providing additional security from intrusion. The bull nose of the lower probe assembly rests in a $60^{\circ}$ center bore on the sliding door, ensuring that the probe must be lifted slightly by the logging winch before the door can be opened.

For transportation and storage, the cap is fastened to the body by seven, high-strength, 1/2-13 UNC hexagonal-head cap screws. The configuration of the joint between cap and body was selected to provide additional surfaces to aid the closure bolts in absorbing sheer stresses if the cask were accidentally dropped. The entire cask assembly is lifted using a single, pivoting, eyebolttype shackle, which is also used for tie-down during shipment.

A pocket is provided in the cap for installation of a microswitch that indicates when the probe is above ground level. An alarm is activated if the gamma;ray source does not remain in the storage position until the beryllium converter is at least $46 \mathrm{~cm}$ (18 in.) below ground level. Thus, this safety-interlock system effectively prevents photoneutron production above ground.

The design of the cask in the cap area was optimized, with respect to withstanding stresses encountered in an accidental drop, by fabricating the enclosures for the depleted uranium of only two pieces of stainless steel. This approach reduces the number of external weld joints required to enclose the cap to only one. To further reinforce the cap, the single-piece, top outer shell is constructed with a high-strength stainless steel. Finally, a tungsten rod is threaded into the bottom center of the cap and protrudes into the source-drive channel of the lower probe assembly to reduce the radiation dose at the top of the cask during shipment.

A triangular base plate has been fabricated to provide reliable leveling and centering of the cask over a borehole. Adjustable legs with swivel feet support the base plate, which has three guide pins to align the bore of the cask with the throughhole in the plate. 


\section{APPENDIX B}

\section{ANALYSIS OF GRAND JUNCTION CALIBRATION MODEL SAMPLES}

A series of crushed coticrete samples obtained at the time the models were poured was sent to Los Alamos by BFEC. $A$ list of the samples is given in Table B-I. The designation A-2-T refers to the top zone of model A-2. Sample numbers have also been assigned to account for cases in which more than one sample was tested in a given zorie.

The arialytical chemistry measurements on the samples discussed above were all performed by the Los Alamos Analytical and Instrumental Chemistry Group. The measurement program pursued had two fundamental goals: (1) to confirm the assignied uranium ore grade for model A-5-B and (2) to determine the presence or absence of any, neutron poisons in A-5-B that might depress the measured photoneutron-probe signal.

The initial uranium concentration measuremerits were performed by $x$-ray fluorescence (X.RF) using standards

TABLE B-I. Crushed Concrete Samples Used in Analytical Chemistry Tests at Los Alamos

\begin{tabular}{cc}
\hline Model, Zone & Sample Number \\
\hline A-2-T & 32279 \\
A-2-C & 32205 \\
A-3-T & 32286 \\
A-5-T & 31185 \\
A-5-T & 31187 \\
A-5-C & 32251 \\
A-5-B & 31178 \\
A-5-B & 31180 \\
A-6-B & 31192 \\
A-6-B & 31194 \\
A-6-T & 31199 \\
A-6-T & 31201 \\
D-barren & 47718 \\
D-barren & 47720 \\
D-ore & 47682 \\
D-ore & 47700 \\
Silica-1 & -- \\
Silica-2 &.-- \\
Al O &.-- \\
D Model & - \\
\hline
\end{tabular}

prepared with New Brunswick Laboratory reference material in crushed concrete matrices. The results of these measurements are given in Table B-II as micrograms per gram of the element listed. Since the XRF measurement system is automated, 11 other elements were also analyzed simultaneously. Referring back to Table B-I, the results are generally as expected with ore zones having substantial uranium content and barren zones containing very low levels of uranium. A few of the samples contained measurable quantities of other elements, e.g., A-5-B, nickel and arsenic; D-ore, copper; silica $I$ and 2, tungsten and selenium. The high tungsten values are due to grinding the silica 1 and 2 samples in a tungsten-carbide mortar before analysis.

The uranium results are compared to the assigned ore grades in Table B-III. In general, the XRF results for uranium are lower, but model A-5-B agrees very well. As a further check, samples from A-5-T and A-2-C were each analyzed by isotope dilution mass spectrometry (IDMS). In this method the samples are dissolved in a mixture of hydrochloric, nitric, and hydrofluoric acids and a known amount of ${ }^{233} \mathrm{U}$ is added as a standard. The results are again compared to the assigned ore grades in Table B-IV. Three smaller samples were analyzed from each larger sample, and are listed individually in the table. The purpose of this procedure is to assess inhomogeneities in the larger samples. The results for models A-5-B and A-2-C are in reasonable agreement with the assigned ore grades and do not show serious inhomogeneities. The measurements of model A-5-T, on the other hand, do not agree and the smaller sample IDMS results indicate considerable inhomogeneity. It is difficult to assess these results independently with the photoneutron probe since model A-5-T contains boron carbide and the expected signal cannot be predicted on the basis of the measurements obtained from models A-1 to A-3. Although some uncertainty remains in the uranium assay of model A-5-T, this series of measurements does indicate that model A-5-B is reasonably well characterized with respect to uranium content.

Thus, we were led to pursue the only other apparent explanation for the reduced signal observed in model A-5-B: the presence of neutron poisons. To this end, the samples listed in Table I were crudely analyzed for the presence of lithium, boron, cadmium, barium, and 


\begin{tabular}{|c|c|c|c|c|c|c|c|c|c|c|c|c|}
\hline Sample & Ag & $\mathbf{B i}$ & Cd & $\mathrm{Cu}$ & $\mathbf{N b}$ & $\mathbf{N i}$ & $\mathbf{P b}$ & Sn & $\mathbf{w}$ & As & Se & $\mathbf{U}$ \\
\hline 031178 & 4 & 5 & 4 & 9 & 19 & 470 & 39 & 9 & 14 & 914 & 4 & 730 \\
\hline 031180 & 4 & 9 & 4 & 12 & 19 & 420 & 36 & 9 & 14 & 743 & 4 & 710 \\
\hline 031185 & 4 & 4 & 4 & 19 & 19 & 14 & 22 & 9 & 14 & 13 & 4 & 470 \\
\hline 031187 & 4 & 10 & 4 & 12 & 19 & 14 & 34 & 9 & 14 & 4 & 4 & 480 \\
\hline 031192 & 4 & 4 & 4 & 27 & 19 & 14 & 19 & 9 & 14 & 15 & 4 & 500 \\
\hline 031194 & 4 & 6 & 4 & 20 & 19 & 14 & 40 & 9 & 22 & 4 & 4 & 560 \\
\hline 031199 & 4 & 4 & 4 & 17 & 19 & 14 & 24 & 9 & 18 & 7 & 4 & 420 \\
\hline 031201 & 4 & 4 & 4 & 9 & 19 & 14 & 32 & 9 & 14 & 4 & 4 & 490 \\
\hline 032205 & 4 & 4 & 4 & 23 & 19 & 14 & 40 & 9 & 20 & 4 & 4 & 540 \\
\hline 032251 & 4 & 4 & 4 & 10 & 19 & 14 & 10 & 9 & 14 & 9 & 4 & 6 \\
\hline 032279 & 4 & 4 & 4 & 42 & 19 & 14 & 16 & 9 & 14 & 4 & 4 & 20 \\
\hline 032286 & 4 & 4 & 4 & 12 & 19 & 14 & 11 & 9 & 14 & 4 & 4 & 15 \\
\hline 047682 & 4 & 4 & 4 & 2444 & 19 & 18 & 37 & 9 & 14 & 10 & 4 & 590 \\
\hline 047700 & 4 & 4 & 4 & 2453 & 19 & 14 & 33 & 9 & 14 & 16 & 4 & 670 \\
\hline 047718 & 4 & 4 & 4 & 21 & 28 & 14 & 22 & 9 & 14 & 4 & 4 & 7 \\
\hline 047720 & 4 & 4 & 4 & 35 & 19 & 14 & 17 & 9 & 14 & 7 & 4 & 4 \\
\hline SILICAI & 4 & 4 & 4 & 40 & 19 & 14 & 4 & 9 & 4325 & 4 & 37 & 4 \\
\hline SILICA2 & 4 & 4 & 4 & 43 & 19 & 14 & 4 & 9 & 6438 & 4 & 49 & 4 \\
\hline
\end{tabular}

Detection

\begin{tabular}{llllllllllllll} 
Limits & 5 & 5 & 5 & & 9 & 19 & 14 & 5 & 10 & 15 & 5 & 5 & 5 \\
\hline
\end{tabular}

\begin{tabular}{ccc}
\hline \hline \multirow{2}{*}{ TABLE B-III. Comparison of Assigned Ore Grades and } \\
$\begin{array}{c}\text { Los Alamos X-Ray Fluorescence } \\
\text { Measurements }\end{array}$ \\
\cline { 2 - 3 } Model, Zone & \multicolumn{3}{c}{$\left(\mu \mathrm{g} / \mathrm{g} \mathrm{U}_{3} \mathrm{O}_{3}\right)$} \\
\hline Assigned Ore Grade Los Alamos XRF \\
A-2-C & $757 \pm 42$ & 637 \\
A-5-T & $780 \pm 32$ & 560 \\
A-5-B & $824 \pm 91$ & 849 \\
A-6-B & $700 \pm 149$ & 625 \\
A-6-T & $688 \pm 73$ & 537 \\
D-Ore & $797 \pm 55$ & 743 \\
\hline
\end{tabular}

gadolinium by atomic emission spectroscopy. The results of these measuremeits are presented in Table B-V. The most interesting feature of the table is that both models A-5-T and A-5-B have relatively high concentrations of boron. The top section was purposely loaded with $\mathrm{B}_{4} \mathrm{C}$ to assess the effects of boron on uranium assay by active neutron interrogation, but the bottom section was thought to have only trace quantities. The boron assay of

\begin{tabular}{|c|c|c|c|c|}
\hline \multicolumn{5}{|c|}{ TABLE B-IV. Comparison of Assi } \\
\hline $\begin{array}{c}\text { Model, } \\
\text { Zone }\end{array}$ & $\begin{array}{l}\text { Sample } \\
\text { Number }\end{array}$ & $\begin{array}{c}\text { Sample } \\
\text { Weight } \\
\text { (mg) }\end{array}$ & $\begin{array}{c}\text { (IDMS) } \\
\mu \mathrm{g} / \mathrm{g} \\
\mathrm{U}_{3} \mathrm{O}_{\mathbf{3}}\end{array}$ & $\begin{array}{c}\text { Assigned } \\
\text { Ore } \\
\text { Grades }\end{array}$ \\
\hline A-5-B & 31178 & $\begin{array}{l}100 \\
24.8 \\
29.2\end{array}$ & $\begin{array}{l}844 \\
895 \\
852\end{array}$ & 829 \\
\hline A-5-T & 31185 & $\begin{array}{l}100 \\
25.0 \\
23.6\end{array}$ & $\begin{array}{l}625 \\
591 \\
700\end{array}$ & 780 \\
\hline A-2-C & 32205 & $\begin{array}{c}100 \\
24.7 \\
25.8\end{array}$ & $\begin{array}{l}730 \\
744 \\
784\end{array}$ & 757 \\
\hline
\end{tabular}

models A-5-T and A-5-B was repeated at higher precision and gave values of 285 and $335 \mu \mathrm{g} / \mathrm{g}( \pm 20 \%)$, respectively. 


\begin{tabular}{|c|c|c|c|c|c|c|}
\hline \multicolumn{7}{|c|}{$\begin{array}{l}\text { TABLE B-V. Atomic Emission Spectroscopy Analysis of } \\
\text { Crushed Concrete Samples for Lithium, } \\
\text { Boron, Cadmium, Barium, and Gadolinium }\end{array}$} \\
\hline $\begin{array}{l}\text { Model, } \\
\text { Zone }\end{array}$ & $\begin{array}{l}\text { Sample } \\
\text { Number }\end{array}$ & $\mathbf{L i}$ & B & $\mathrm{Cd}$ & $\mathbf{B a}$ & Gd \\
\hline \multirow[t]{2}{*}{ A-5-B } & 31178 & $25^{1}$ & 400 & 20 & 500 & $<50$ \\
\hline & 31180 & 25 & 400 & 20 & 700 & $<50$ \\
\hline \multirow[t]{2}{*}{ A-5-T } & 31185 & 20 & 300 & $<10$ & 800 & $<50$ \\
\hline & 31187 & 20 & 250 & $<10$ & 800 & $<50$ \\
\hline \multirow[t]{2}{*}{$A-6-B$} & 31191 & 20 & 10 & $<10$ & 800 & $<50$ \\
\hline & 31194 & 20 & 10 & $<10^{b}$ & 700 & $<50$ \\
\hline \multirow[t]{2}{*}{$A-6-T$} & 31199 & $<20$ & 15 & $<10$ & 600 & $<50$ \\
\hline & 31201 & $<20$ & 15 & $<10$ & 600 & $<50$ \\
\hline$A-2-C$ & 32205 & 20 & 15 & $<10$ & 800 & $<50$ \\
\hline A-5-C & 32251 & 20 & 15 & $<10$ & 700 & $<\mathbf{5 0}$ \\
\hline A-2-T & 32279 & 20 & 15 & $<10$ & 800 & $<50$ \\
\hline A-3-T & 32286 & 20 & 10 & $<10$ & 800 & $<50$ \\
\hline \multirow{2}{*}{ D-Ore } & 47682 & 20 & 15 & $<10$ & 700 & $<50$ \\
\hline & 47700 & 20 & 15 & $<10$ & 800 & $<50$ \\
\hline \multirow[t]{2}{*}{ D-Barren } & 47718 & 20 & 10 & $<10$ & 700 & $<50$ \\
\hline & 47720 & 20 & 10 & $<10$ & 700 & $<50$ \\
\hline SILICA 1 & --- & $<20$ & $<10$ & $<10$ & $<10$ & $<50$ \\
\hline SILICA 2 & --- & $<20$ & $<10$ & $<10$ & $<10$ & $<50$ \\
\hline
\end{tabular}

"Results expressed in $\mu \mathrm{g} / \mathrm{g}$.

${ }^{b} A<$ symbol represents the limit of detection. All other results have a precision of $\pm 50 \%$.

Model A-5-B was designed to measure the effect of bulk density on uranium assay by active neutron interrogation. The density of the model was increased relative to models A-1, A-2, and A-3 by substituting corundum for sand in the concrete mix. A sample of the corundum was obtained from Grand Junction, analyzed, and found to contain $570 \mu \mathrm{g} / \mathrm{g}$ boron $( \pm 20 \%)$. Thus, the anomalous results obtained in model A-5-B during the November;
1979, calibration tests are now well understood. The suppression of the signal in model A-5-B relative to A-1, A-2, and A-3 was due to a boron contaminant introduced in the matrix material. The assessment of the effects of neutron poisons on probe performance is somewhat clouded by the differences observed between the assigned ore grade and the analytical chemistry measurements for model A-5-T. 


\section{APPENDIX C}

\section{LOGGGING VEHICLE PREPARATION AND OPERATION}

The four-wheel drive truck, on loan from BFEC/DOQE in Grand Junction was only partially equipped when receiyed. The enclosed truck bed had heen outfitted with air conditioning and 110 -V-ac outlets powered by a gaşoline-fueled generattor. The truck-bed enclosure contained a variable-speed winch with approximately 1000 $\mathrm{m}$ ( $3300 \mathrm{ft})$ of four conductor (4HO) logging cable.

A strain gauge and cable depth counter were added to the winch at Los Alamos. There was a facility for detecting strain on the cable; however, there was no readout of the strain and the mechanissm satyrated at a strain less than the weight of our probe $(43 \mathrm{~kg}, 95 \mathrm{lbs})$. The strain sensing mechanism was strengthened so that saturation was reached at $\sim 140 \mathrm{~kg}(310 \mathrm{lbs})$. An electronic device was designed and fabricated to sense the mechanical strain gauge and produce a numerical LED readout proportional to cable tension. The design included set points for minimum and maximum strain. With this feature enabled, the winch was automatically stopped when the cable tension was outside the set-point boundaries.

The winch contained a mechanical device th.at uses a light-coupled pair viewing a slotted wheel for detecting cable motion. One pulse is generated for each $3.2 \mathrm{~mm}$ ( $1 / 8$ in.) of cable movement. A circuit was designed to count these pulses (noting direction of cable travel) and provide LED readouts or the probe depth and rate of cravel. This information is transmitted to the on-board computer (described below) through a parallel interface to permit the logging data to be labeled with the appropriate depths. In addition, a new speed controller was installed on the winch motor to allow more stable operation at low speeds.

The lower section of the photoneutron probe, containing the gamma-ray source, resides in a depleted uranium storage cask weighing $\sim 750 \mathrm{~kg}$ ( $1650 \mathrm{lbs})$. A system was devised for transporting the cask to the logging site and positioning it over the hole to be logged. Inside the truck the cask rests on a support plate mounted on two ritils that extend out over the rear bumper as shown in Fif C-1. During transit, the cask is capped with a lid outfitted with a lifting eye, the support plate is bolted ipto place, and the cask is strapped to the truck bed. Once the logging vehicle is in position near the hole, triangular support and leveling plate is positioned over tho hole.
The bolts and straps holding the cask during transit are removed, and it is rolled along the rails to a position outside the truck, over the rear bumper platform. The entire cask is lifted from the movable plate onto the leveling plate using a hydraulically powered crane mounted on the rear bumper. The crane, a Hiab model $250, *$ is capable of smooth, precise motion in three dimensions allowing convenient transfer of the cask to and from the truck (Fig. C-2.) After positioning the cask over the hole, the lid is unbolted and lifted back onto the truck using the crane. At this time a pulley, through which the logging cable is threaded, is mounted on the end of the crane boom. The upper portion of the probe is attached to the logging cable and lowered onto the lower portion using the crane and winch. After the two halves of the probe are coupled, a trap door in the bottom of the cask is opened and the probe is lowered into the hole using the winch.

A complete computer system featuring a Nuclear Data Corporation model ND660,** LSI-11 $\dagger$-based multichannel analyzer (MCA) was installed in the truck. A dual-floppy-disk drive is included for system software storage and recording of logging data. The computer is interfaced to a Digital Equipment Corporation LA $120^{\dagger}$ keyboard/line printer. This is used for program initialization, listings, and a simple plot of the data as it is acquired. The signals are passed from the probe controller box to the computer/MCA using standard NIM modules. The relay rack containing the computer, disk arives, CRT, NIM bin, probe controller, and depth gauge readout is mounted together with the line printer onto a plate that is shock mounted to the bed and one wall of the truck (Fig. C-3).

The logging truck borrowed from DOE/BFEC, Grand Junction, and outfitted by Los Alamos, was used for three field trials of the photoneutron logging tool. Other than insufficient electrical noise isolation/suppression between devices, the system was found to be reliable and convenient.

\footnotetext{
*Hiab Cranes \& Loaders, Inc., Hiab Circle, Newark, DE 19711.

* Nuclear Data, Inc., Gulf \& Mescham Roada, Schaumbuns, IL 60196.

+Digital Equipment Corporation, Maynard, MA 01754.
} 


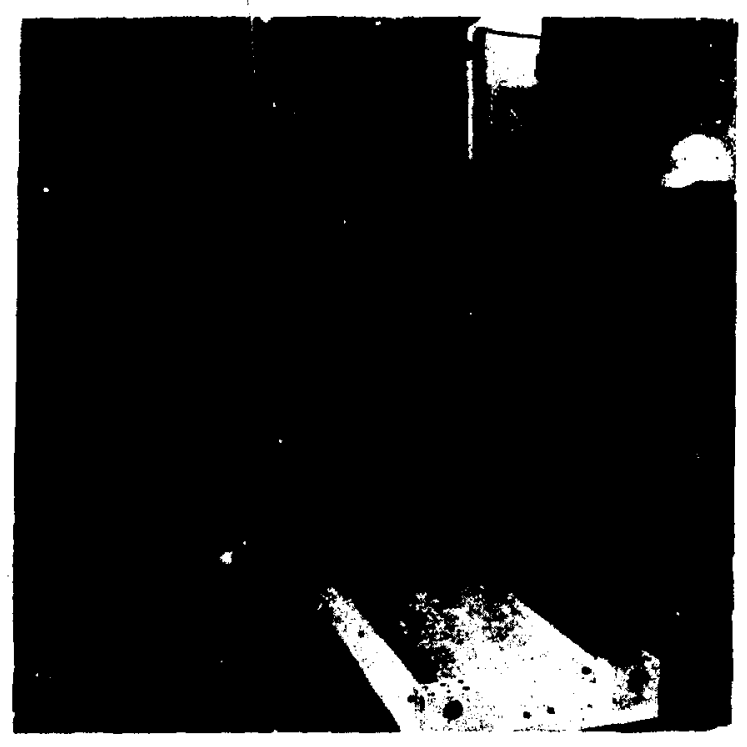

Fis. C-1. View of logging truck through rear double doors thowing source transport cauk restin on movable platiorm. The cask is shown atrapped down for transit. The Nal and photoneutron probes can be ween to the left of the cask buide rails.

Fis. C-2. View of the rear of the logging truck showing crane that is used for positioning of source call containing the lower half of the probe.

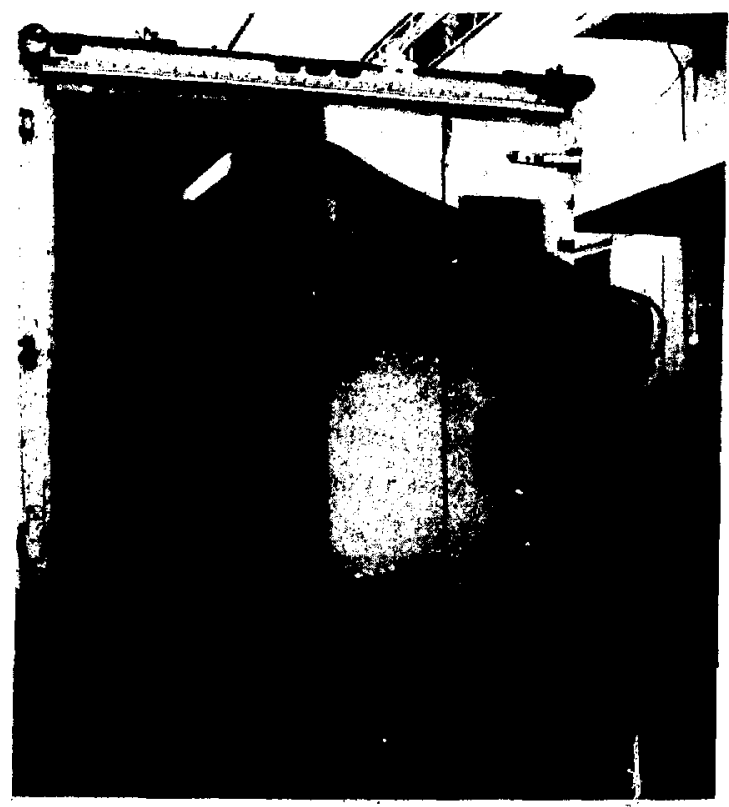


Fig. C-3. View through side door of lotelng truck showing the relay rack containing all uphole electronics and computer-based MCA. The line printer is on the left-hand side of the thockmounted plate.

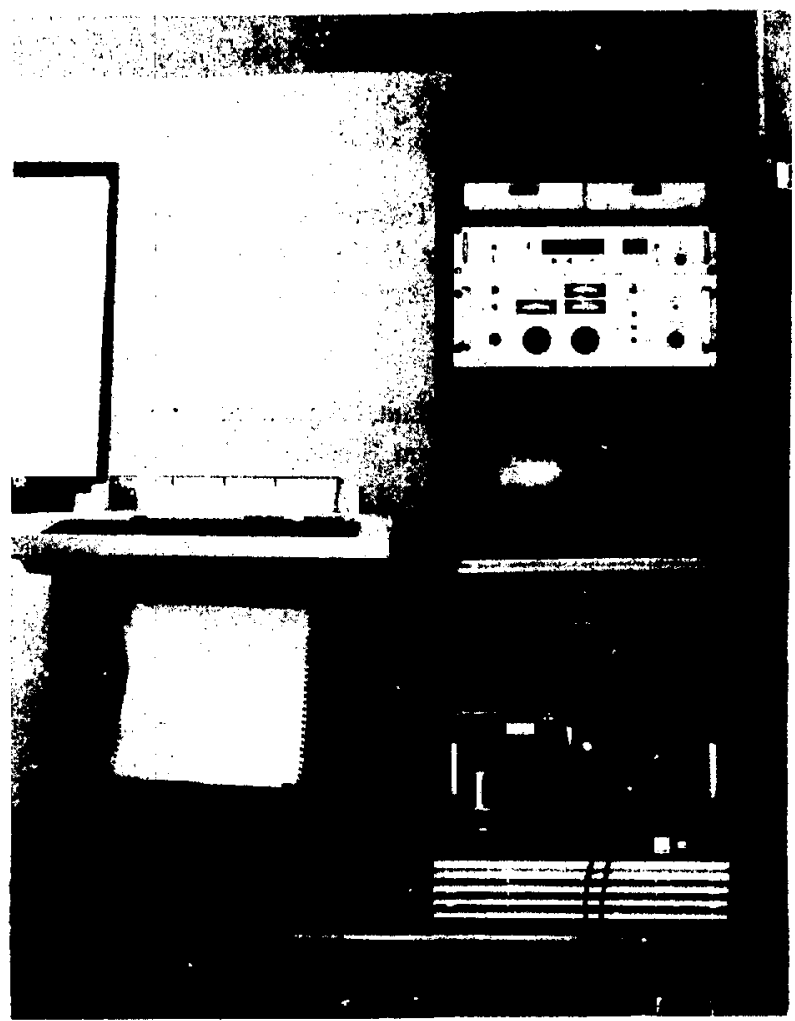

4. M. P. Baker and H. O. Menlove, "NDA Technology for Uranium Resource Evaluation," January 1-March 31, 1977, Los Alamos Scientific Laboratory report LA-6840 (June 1977), pp. 16-22.

5. M. L. Evans, H. O. Menlove, and M. P. Baker, "Subthreshold Neutron Interrogator for Detection of Radioactive Materials," US Patent No. 4201 912, May 1980.

6. Carl J. Koizumi, "Logging Calibration Models for Fission Neutron Sondes," Bendix Field Engineering Corporation, Open File No. GJBX-267(81), US Department of Energy, Grand Junction, Colorado, October 1979.

7. David Stromswold and Robert D. Wilson, "Spectral Gamma-Ray Borehole Logging, Technical Note 1, Methods of Calibration," Subsurface Systems Department, Bendix Field Engineering Corporation (September 1978). 
8. T. Marks, "NDA Technology for Uranium Resource Evaluation, January 1, 1979-June 30, 1979," Las Alamos Scientific Laboratory report LA-8321 (April 1980), pp. 15-18.

9. M. P. Baker, "NDA Technology for Uranium Resource Evaluation, July 1-December 31, 1978," Los Alamos Scientific Laboratory report IAA-8065 (November 1979), pp. 7-8.

10. J. R. Beyster and L. A. Kull, "Safeguards Applications for Isotopic Neutron Sources," Brookhaven National Laboratory report BNL-50267, T-596, (June 1970).
11. M. P. Baker, "NDA Technology for Uranium Resource Evaluation, April 1-June 30, 1977," Los Alamos Scientific Laboratory report LA-6996 (October 1977), pp. 13-15.

12. M. P. Baker, "NDA Technology for Uranium Resource Evaluation, October-December, 1977," Los Alamos Scientific Laboratory report LA-7251 (April 1978), pp. 6-8.

13. M. P. Baker, "NDA Technology for Uranium Resources Evaluation, July 1-September 30, 1977," Los Alamos Scientific Laboratory report LA-7139 (February 1978), pp. 20-21. 